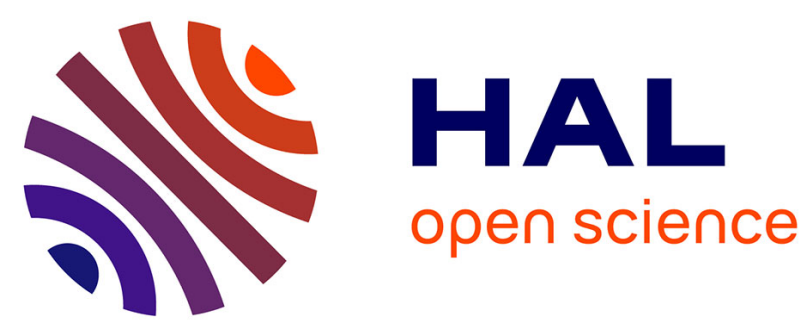

\title{
Unhealthy behaviours and disability in older adults: three-City Dijon cohort study.
}

Fanny Artaud, Aline Dugravot, Séverine Sabia, Archana Singh-Manoux, Christophe Tzourio, Alexis Elbaz

\section{- To cite this version:}

Fanny Artaud, Aline Dugravot, Séverine Sabia, Archana Singh-Manoux, Christophe Tzourio, et al.. Unhealthy behaviours and disability in older adults: three-City Dijon cohort study.. BMJ / BMJ (CLINICAL RESEARCH ED); Br Med J; British Medical Journal; Brit Med J, 2012, 347 (jul23 1), pp.f4240. 10.1136/bmj.f4240 . inserm-01147229

HAL Id: inserm-01147229 https://www.hal.inserm.fr/inserm-01147229

Submitted on 30 Apr 2015

HAL is a multi-disciplinary open access archive for the deposit and dissemination of scientific research documents, whether they are published or not. The documents may come from teaching and research institutions in France or abroad, or from public or private research centers.
L'archive ouverte pluridisciplinaire HAL, est destinée au dépôt et à la diffusion de documents scientifiques de niveau recherche, publiés ou non, émanant des établissements d'enseignement et de recherche français ou étrangers, des laboratoires publics ou privés. 


\title{
Unhealthy behaviours and disability in older adults: Three-City Dijon cohort study
}

\author{
@ @Q $\Theta$ OPEN ACCESS
}

\author{
Fanny Artaud $P h D$ candidate ${ }^{12}$, Aline Dugravot statistician ${ }^{12}$, Séverine Sabia research associate ${ }^{3}$, \\ Archana Singh-Manoux research director ${ }^{1234}$, Christophe Tzourio professor of epidemiology ${ }^{56}$, \\ Alexis Elbaz research director ${ }^{123}$
}

${ }^{1}$ INSERM, Centre for research in Epidemiology and Population Health (CESP), U1018, Social and occupational determinants of health, F-94807, Villejuif, France; ${ }^{2}$ Université de Versailles St-Quentin, UMRS 1018, F-78035, Versailles, France; ${ }^{3}$ Department of Epidemiology and Public Health, University College London, London, UK; ${ }^{4}$ Centre de Gérontologie, Hôpital Ste Périne, AP-HP, France; ${ }^{5}$ INSERM U708, Neuroepidemiology, Bordeaux, France; ${ }^{6}$ Université de Victor Segalen Bordeaux 2, Bordeaux, France

\begin{abstract}
Objectives To examine the individual and combined associations of unhealthy behaviours (low/intermediate physical activity, consuming fruit and vegetables less than once a day, current smoking/short term ex-smoking, never/former/heavy alcohol drinking), assessed at start of follow-up, with hazard of disability among older French adults and to assess the role of potential mediators, assessed repeatedly, of these associations.

Design Population based cohort study.

Setting Dijon centre of Three-City study.

Participants 3982 (2410 (60.5\%) women) French community dwellers aged 65 or over included during 1999-2001; participants were disability-free at baseline when health behaviours were assessed.

Main outcome measure Hierarchical indicator of disability (no, light, moderate, severe) combining data from three disability scales (mobility, instrumental activities of daily living, basic activities of daily living) assessed five times between 2001 and 2012.

Results During the 12 year follow-up, 1236 participants (861 (69.7\%) women) developed moderate or severe disability. Interval censored survival analyses (adjusted for age, sex, marital status, and education) showed low/intermediate physical activity (hazard ratio 1.72, 95\% confidence interval 1.48 to 2.00 ), consuming fruit and vegetables less than once a day (1.24, 1.10 to 1.41), and current smoking/short term ex-smoking $(1.26,1.05$ to 1.50$)$ to be independently associated with an increased hazard of disability, whereas no robust association with alcohol consumption was found. The hazard of disability increased progressively with the number of unhealthy behaviours independently associated with disability $(P<0.001)$; participants with three unhealthy behaviours had a 2.53 (1.86 to 3.43)-fold increased hazard of disability compared with those with none. Reverse causation bias was verified by excluding
\end{abstract}

participants who developed disability in the first four years of follow-up; these analyses on 890 disability events yielded results similar to those in the main analysis. $30.5 \%$ of the association between the unhealthy behaviours score and disability was explained by body mass index, cognitive function, depressive symptoms, trauma, chronic conditions, and cardiovascular disease and its risk factors; the main contributors were chronic conditions and, to a lesser extent, depressive symptoms, trauma, and body mass index.

Conclusions An unhealthy lifestyle is associated with greater hazard of incident disability, and the hazard increases progressively with the number of unhealthy behaviours. Chronic conditions, depressive symptoms, trauma, and body mass index partially explained this association.

\section{Introduction}

Disability is commonly defined as a "difficulty or dependency in carrying out activities essential to independent living, including essential roles, tasks needed for self-care and living independently in a home, and desired activities important to one's quality of life."1 As the risk of disability increases with age, the burden of disability is expected to increase owing to the ageing of populations worldwide, despite declining trends in prevalence of disability in some European studies. ${ }^{23}$ The number of disabled people in France is projected to increase by $50 \%$ between 2000 and $2040 .{ }^{4}$ Identifying potentially modifiable risks factors of disability may help to define preventive strategies and slow this progression.

Previous research has shown that unhealthy behaviours (physical inactivity, poor diet, smoking, alcohol abstinence or consumption beyond recommended limits) have an adverse effect on health. Increasing evidence shows that some unhealthy 
behaviours tend to cluster in individuals. ${ }^{56}$ The risk of obesity, diabetes, cancer, poor cognitive function, stroke, sudden cardiac death, and mortality increases with the number of unhealthy behaviours. ${ }^{7-18}$ Unhealthy behaviours such as lack of physical activity, poor diet, smoking, alcohol abstinence, and heavy alcohol consumption have also been shown to be associated with an increased risk of disability in older people. ${ }^{19-28}$ However, few studies have examined the combined effect of unhealthy behaviours on disability. ${ }^{21}{ }^{29}$ Furthermore, pathways involved in the association between unhealthy behaviours and disability are poorly understood.

Our objective was to investigate the relation between unhealthy behaviours, with each behaviour examined separately and in combination, and the hazard of disability over a 12 year follow-up in a cohort of French older people from the Dijon centre of the Three-City (3C) study. To assess the robustness of associations between unhealthy behaviours and disability, we used repeated measures of disability and a statistical method that takes into account interval censoring and competing risks of death. A further objective was to examine the role of potential mediators (body mass index, cognitive function, depressive symptoms, trauma, chronic conditions, and cardiovascular disease and its risk factors) in the association between unhealthy behaviours and disability.

\section{Methods \\ Study population}

The $3 \mathrm{C}$ study is a prospective cohort study that recruited community dwelling older people aged 65 years or over from electoral rolls in three French cities (Bordeaux, Dijon, Montpellier) in 1999-2001. ${ }^{31}$ The first six years of follow-up were common to the three study centres; subsequently, each centre had specific aims. The study reported here is based on data from Dijon $(n=4931$; response rate $35 \%)$, where investigators were particularly interested in physical function and disability.

After the baseline examination (wave 0), participants were interviewed in person after two (wave 1, 2001-02), four (wave 2, 2003-04), seven (wave 4, 2006-07), nine (wave 5, 2008-09), and 11 years (wave 6, 2010-12); wave 3 (2005-06) consisted of a self administered questionnaire that did not include disability measures. During the follow-up, every effort was made to contact participants directly or through their relatives and physicians. Over the follow-up, an increasing proportion of participants were seen at their residence (including institutions) rather than at the study centre.

\section{Disability}

Disability status was assessed six times over 12 years, at baseline and waves $1,2,4,5$, and 6 . Three domains of disability were assessed (see supplementary methods): mobility, instrumental activities of daily living, and basic activities of daily living. Mobility was assessed with the French translation of the Rosow and Breslau scale, which evaluates the ability to do heavy work around the house, walk half a mile, and climb stairs. ${ }^{32}$ The French version of the Lawton-Brody instrumental activities of daily living scale evaluates the ability to use a telephone, manage drugs and money, use public or private transport, and do shopping and, additionally for women, to prepare meals and do housework and laundry. ${ }^{33}$ Basic activities of daily living were assessed through the French version of the Katz scale that evaluates whether participants need help with bathing, dressing, toileting, transferring from bed to chair, and eating; we excluded incontinence as it reflects organ impairment rather than functional limitation. ${ }^{34}$ For each disability domain, we considered participants to be disabled if they could not perform at least one activity without a given level of help, as defined by the respective instrument.

We constructed a hierarchical disability indicator, ${ }^{35}$ which defines four levels of increasing disability by summing up responses to the three dichotomised disability items in a hierarchy $(0=$ fully independent; $1=$ dependent only in relation to the Rosow scale; $2=$ dependent on the Rosow and instrumental activities of daily living scales but not the basic activities of daily living scale; $3=$ dependent in all domains). This approach has the advantage of taking three disability domains into account simultaneously; this indicator has a reproducibility coefficient of 0.99 and a scalability coefficient of $0.98 .{ }^{35}$ Few people were disabled in the three domains, and we compared people in groups $2 / 3$ (moderate/severe) with those in groups $0 / 1$ (no/light disability).

\section{Unhealthy behaviours}

Data on health behaviours came from the baseline questionnaire. We categorised behaviours as healthy/unhealthy a priori on the basis of previous findings; we did sensitivity analyses to ensure that findings were robust to categorisations used in the analysis. Physical activity was assessed through questions on frequency of daily walking and exercise (for example, gym, swimming, cycling) and categorised as high (walking more than one hour a day and exercising more than once a week), low (walking less than one hour a day and exercising less than once a week), and intermediate (all others). We considered low or intermediate physical activity levels to be unhealthy behaviours.

Consumption of fruit and vegetables was assessed through questions on frequency of consumption of raw and cooked fruit and vegetables. Responses were on a six point scale ("never" to "at least once a day"). We classified participants as consuming fruit or vegetables at least once a day, four to six times a week, and less than four times a week. We considered eating fruit or vegetables less than once a day to be an unhealthy behaviour in the analysis.

Smoking status was assessed through questions on cigarettes smoked during different periods of adult life and age at which participants started or quit smoking. Using these data, we categorised smoking status as never smoker, long term ex-smoker (quit smoking at least 15 years before baseline), short term ex-smoker (quit smoking less than 15 years before baseline), and current smoker. The 15 year cut-off allows a distinction to be made between people who stopped smoking in midlife and those who stopped smoking later in life, close to the baseline examination, when smoking cessation is more likely to be due to health problems. ${ }^{15}{ }^{29}$ We considered current smoking and short term ex-smoking to be unhealthy behaviours.

Consumption of alcohol was assessed by questions on weekly number of alcoholic drinks. We categorised alcohol consumption as never drinker, former drinker, light to moderate drinker (1-21 alcoholic drinks a week for men and 1-14 for women), ${ }^{37}$ and heavy drinker. Other studies among older adults have also used this definition. ${ }^{12} 16{ }^{38} \mathrm{We}$ considered alcohol drinking other than light to moderate to be an unhealthy behaviour.

\section{Covariates}

Baseline sociodemographic measures considered to be potential confounders included age, sex, education (no education/primary school, secondary school, high school/university), and marital status (married, divorced/separated/widowed, single). 
On the basis of previous literature, we identified characteristics that may mediate the relation between unhealthy behaviours and disability. Cardiovascular disease, stroke, diabetes, cognitive and visual impairment, dyspnoea, and depression have been associated with the hierarchical indicator of disability. ${ }^{36}$ Depressive symptoms, falls, and hearing/visual impairment have been associated with greater risk of incident disability in basic activities of daily living in women. ${ }^{39}$ Finally, high body mass index, osteoarthritis, hip fracture, and cancer are also associated with an increased risk of disability. ${ }^{40-43}$ These covariates were assessed at baseline and each wave of data collection.

Body mass index was calculated as weight divided by height squared and categorised as less than 25 (normal weight), 25 to less than 30 (overweight), and 30 or above (obese). Cognitive function was assessed through a global test (mini-mental state examination), with higher scores corresponding to better function; we categorised the scores in thirds. Depressive symptoms were measured by the Centre for Epidemiologic Studies depression scale; scores of 16 and above correspond to high depressive symptoms. ${ }^{44}$ Trauma included a history of bone fracture or recurrent falls (at least two falls) in the previous two years. Chronic conditions included self reported diabetes, Parkinson's disease, vision difficulties (difficulty in recognising familiar faces at a distance of $4 \mathrm{~m}$ or less, with or without glasses), deafness, dyspnoea (New York Heart Association classification), non-steroidal anti-inflammatory drug use for joint pain, and cancer. Cardiovascular disease and its risk factors included stroke, coronary heart disease, lower limb arteritis, hypertension (systolic blood pressure $\geq 140 \mathrm{~mm} \mathrm{Hg}$, diastolic blood pressure $\geq 90 \mathrm{~mm} \mathrm{Hg}$, or antihypertensive drugs), and lipid lowering drugs as a surrogate for hypercholesterolaemia. Incident stroke and coronary heart disease events were validated by expert committees set up by the study to classify these events by using hospital and medical records. ${ }^{45}$

\section{Statistical analysis}

We described participants' characteristics as a function of disability status at the end of the follow-up and the number of unhealthy behaviours at baseline. Disability was assessed at each wave, but the precise date of onset was unknown. In addition, participants could have become disabled between two visits and died before the next visit without having been seen and identified as being disabled. To take into account the interval censored nature of our data and competing risks of death, we used a multistate model with transitions between three states (disease-free, disabled, dead) and a Weibull distribution for the hazards. This approach takes interval censoring into account and allows those who die between two waves of data collection to become disabled before dying. ${ }^{46}$ All participants who developed disability over the follow-up were interval censored between the wave when disability was ascertained and the previous wave. Participants who remained alive without disability over the follow-up were right censored at the last wave. We used age as the timescale, with entry time defined as the participant's age at baseline. Models were adjusted for confounders (sex, education, marital status) and the interaction between sex and marital status, because preliminary analyses showed that the association between marital status and disability was modified by sex.

We estimated the hazard of disability over the follow-up associated with baseline unhealthy behaviours, for each behaviour on its own and in combination. We firstly did analyses for the dichotomised hierarchical indicator of disability and then repeated them for each domain separately; because few participants were disabled in basic activities of daily living, we combined those disabled in basic activities of daily living or instrumental activities of daily living. ${ }^{23}$ People disabled for the corresponding domain at baseline were excluded from the analyses.

We first built separate models for each unhealthy behaviour (model 1). To assess their independent effects, we then included all unhealthy behaviours in a single multivariable model, either as categorical (model 2) or binary variables (unhealthy/healthy) (model 3). Finally, we examined the relation between disability and an unhealthy behaviours score (hazard ratio per unit increase in the unhealthy behaviours score), constructed as the number of unhealthy behaviours independently associated with disability in model 3 (low/intermediate physical activity; consumption of fruit and vegetables less than once a day; current smoking and short term ex-smoking) and ranging from zero to three. ${ }^{9}$ 12-15

Interactions between unhealthy behaviours and sex were not statistically significant; our primary analyses are therefore reported for men and women combined, with adjustment for sex. In supplementary tables, we show analyses stratified by sex because the hazard of disability was higher in women and behaviours varied as a function of sex.

We ran several sensitivity analyses. We examined alternative definitions of unhealthy behaviours to assess the pertinence of the a priori definitions used. Disability is a progressive process, and declining function preceding onset of disability may influence health behaviours at baseline, particularly for disability occurring shortly after the baseline examination (reverse causation); to assess this potential bias, we excluded participants with incident disability at waves 1 or 2 (that is, those who developed disability during the first four years of the follow-up). Our main analyses do not take into account the possibility that some participants may recover from disability; we therefore excluded these cases and repeated the analysis. Time to event analyses require a binary outcome; to take into account the ordinal nature of the disability indicator, we used multinomial logistic regression at each wave, with the hierarchical score as the dependent variable.

We examined the extent to which the association between unhealthy behaviours and disability was explained by mediators (body mass index, cognitive function, depressive symptoms, trauma, chronic conditions, cardiovascular disease and risk factors) by estimating the percentage reduction as $100 \times\left(\beta_{\text {model }}\right.$ $\left.{ }_{1}-\beta_{\text {model }}\right) / \beta_{\text {model } 1}$, where $\beta$ is a regression coefficient from a survival model including time dependent covariates.

We did analyses with SAS 9.3 and the R (2.14) SmoothHazard package. $\mathrm{P}$ values are two sided, and we considered those of 0.05 or below to be statistically significant.

\section{Results}

At baseline, 488 (9.9\%) of 4931 participants were disabled and excluded from the analyses; a further 195 participants dropped out of the study before wave 1 and did not die during the follow-up. These participants were less physically active $(17.7 \%$ $v 24.7 \%$ in the high category; $\mathrm{P}=0.05$ ) and less likely to consume alcohol lightly to moderately $(49.5 \% v 63.7 \%$; $<<0.001)$ than were those who remained in the study; no major differences existed in age, sex, diet, smoking, and number of unhealthy behaviours (all $\mathrm{P}>0.05$ ). Moreover, 266 participants had missing data on at least one health behaviour $(\mathrm{n}=254)$ or the outcome $(n=12)$. Our analyses are therefore based on 3982 participants (2410 (60.5\%) women) (supplementary figure A). Compared with participants included in the analyses, those excluded $(\mathrm{n}=461)$ were older $(75.1 v 73.9$ years; $\mathrm{P}<0.001)$, more likely 
to consume fruit and vegetables less than once a day $(72.1 \% \mathrm{v}$ 66.9\%; age adjusted $\mathrm{P}=0.02$ ), and less likely to drink alcohol lightly to moderately $(56.3 \% \vee 63.7 \%$; age adjusted $\mathrm{P}=0.01)$. No differences existed for sex, physical activity, smoking, and number of unhealthy behaviours (all age adjusted $\mathrm{P}>0.05$ ).

During a total follow-up of 12 years (mean 6.8 (SD 3.4) years), 3982 participants contributed 27141 person years and 1236 (861 (69.7\%) women) developed disability (incidence $45.5 / 1000$ person years). Incidence of disability increased from $3.4 / 1000$ in participants aged 65-70 years to 288.0/1000 in those over 90 years. During the follow-up, 992 participants died, of whom 702 were not disabled at their last examination before death. Among participants who remained disability-free and alive, 937 were last seen at wave 6,296 at wave 5, 293 at wave 4, 361 at wave 2 , and 155 at wave 1 ; no differences existed for diet (age adjusted $\mathrm{P}=0.37$ ), smoking (age adjusted $\mathrm{P}=0.90$ ), and alcohol consumption (age adjusted $\mathrm{P}=0.70$ ) between participants seen at wave 6 and those censored before; participants censored before wave 6 tended to be older $(73.1 v 70.9$ years; $\mathrm{P}<0.001)$ and less physically active $(24.5 \%$ v $37.4 \%$ in the high category; age adjusted $\mathrm{P}<0.001$ ).

Table $1 \Downarrow$ shows participants' characteristics overall and by disability status. Participants who developed disability were older and less likely to be men, less likely to be married, and less educated than were participants without disability. They were also less physically active, consumed fewer fruits and vegetables, and had a higher number of unhealthy behaviours and a worse health profile. Overall, those who became disabled were less often ever-smokers, but this pattern resulted from confounding by sex and age. Unhealthy behaviours clustered in individuals; those with one unhealthy behaviour were more likely to also have other unhealthy behaviours (odds ratios ranging from 1.2 to 1.5 ). Approximately $26 \%$ of participants had one unhealthy behaviour, $42 \%$ had two, $23 \%$ had three, $3 \%$ had four, and $6 \%$ had none. Unhealthy behaviours were more frequent in older participants and in men. In age and sex adjusted analyses, lower education and being married were associated with a greater number of unhealthy behaviours (supplementary table A).

Table $2 \Downarrow$ shows that in separate models for each unhealthy behaviour (model 1), participants reporting low or intermediate physical activity had a 1.76 (95\% confidence interval 1.51 to 2.05)-fold higher hazard of disability. Participants who consumed fruit and vegetables less than once a day had a 1.29 (1.14 to 1.45)-fold increased hazard of disability. Current smokers and short term ex-smokers had a 1.29 (1.09 to 1.54)-fold increased hazard of disability compared with never smokers and long term ex-smokers. Only former drinkers had a higher hazard of disability (hazard ratio $1.49,1.05$ to 2.12 ) compared with light to moderate drinkers. Model 2 included all four unhealthy behaviours simultaneously as categorical variables; hazard ratios were similar to those in model 1. Model 3 corresponds to similar analyses with behaviours simplified as dichotomous variables, showing that smoking, low/intermediate physical activity, and poor diet remained associated with disability.

Supplementary table B shows analyses for mobility and disability in activities of daily living (basic or instrumental). Low/intermediate physical activity and low consumption of fruit and vegetables were associated with impairment of mobility; we found no association for smoking and alcohol. Low/intermediate physical activity, low consumption of fruit and vegetables, and smoking were associated with disability in basic or instrumental activities of daily living, whereas alcohol was not.
Although the interactions between sex and unhealthy behaviours were not statistically significant (all $\mathrm{P}>0.30$ ), stratified analyses showed some sex differences (supplementary table $\mathrm{C}$ ). The association of physical activity with disability was of a similar magnitude in both sexes, and hazard ratios were higher in men than in women for consumption of fruit and vegetables and number of unhealthy behaviours. We found no association with smoking in women; in men, short term ex-smokers had an increased hazard of disability compared with never smokers. For alcohol, we found no association in men; in women, former drinkers had an increased hazard of disability compared with light to moderate drinkers.

The hazard of disability increased with the number of unhealthy behaviours (figure $\downarrow$ ). The hazard ratio per unit increase in the unhealthy behaviour score was 1.39 (1.29 to 1.51) for the hierarchical indicator, 1.24 (1.16 to 1.33 ) for mobility impairment, and 1.31 (1.22 to 1.40) for disability in basic or instrumental activities of daily living. For the hierarchical indicator, participants with three unhealthy behaviours had a 2.53 (1.86 to 3.43)-fold increased hazard of disability. This association seemed stronger in men (hazard ratio $3.23,1.88$ to $5.54)$ than in women $(1.94,1.28$ to 2.95$)$ ( $P$ for difference $=0.60)$ (supplementary table C). Hazard ratios for disability in basic or instrumental activities of daily living $(2.11,1.60$ to 2.78 , overall; $2.40,1.52$ to 3.80 , in men; $1.70,1.14$ to 2.54 , in women) and mobility impairment $(1.91,1.50$ to 2.44 , overall; $2.05,1.43$ to 2.96 , in men; $1.92,1.33$ to 2.79 , in women) were lower. In sensitivity analyses, we added alcohol consumption to the score; hazard ratios increased with the number of unhealthy behaviours but were smaller than hazard ratios based on the original score (supplementary figure B).

We examined alternative definitions of unhealthy behaviours. For physical activity, a small number of people $(\mathrm{n}=212)$ who did not walk but exercised regularly did not have an increased hazard of disability. However, grouping them with those who walked and exercised instead of in the unhealthy category had a small effect (hazard ratio 1.85, 1.61 to 2.12) (supplementary table D). Including this definition in the score of unhealthy behaviours also had little effect (supplementary table E). Using different lag times to distinguish short term and long term ex-smokers had little influence on the association between current smoking/short term ex-smoking and disability (supplementary table F) and minimal influence on the association between the score of unhealthy behaviours and disability (data not shown). For alcohol, we excluded first heavy drinkers and then abstainers from the analyses to assess the suitability of grouping them together and found similar results (supplementary table $\mathrm{G}$ ); using alternative thresholds to define light to moderate drinkers (for example, 1-11 drinks a week; 1-11 drinks a week in men and 1-7 in women) yielded similar conclusions (data not shown).

In further sensitivity analyses, we excluded 346 participants ( $28 \%$ of those who developed disability) who developed disability during the first four years of follow-up; these analyses were based on 2584 participants, of whom 890 developed disability (table $3 \Downarrow$ ). Hazard ratios were similar for physical activity and strengthened for consumption of fruit and vegetables and for smoking compared with original analyses. Conclusions for alcohol consumption were unchanged.

During the follow-up, 297 participants (24\% of those who developed disability) recovered from disability; 243 of them remained disability-free throughout the follow-up. Analyses excluding these participants yielded similar results to those in the main analysis (supplementary table $\mathrm{H}$ ). Analyses based on multinomial logistic regression showed that odds ratios increased 
in both rows and columns, leading us to conclude that for a given number of unhealthy behaviours the hazard increased with increasing levels of disability and that for each level of disability the hazard increased with the number of unhealthy behaviours (supplementary table I).

Table $4 \Downarrow$ shows the role played by potential mediators in the association between the number of unhealthy behaviours and disability. For the score of unhealthy behaviours, $30.5 \%$ of the association was explained by the mediators included in the model. The highest percentage reductions were for chronic conditions (11.5\%), followed by depressive symptoms (9.0\%), trauma $(7.1 \%)$, and body mass index $(5.6 \%)$.

\section{Discussion}

In analyses based on a large cohort of French community dwelling older adults, three modifiable unhealthy behaviours - physical inactivity, poor diet, and smoking — were independently associated with an increased hazard of disability over a 12 year follow-up. The hazard of disability increased progressively with the number of unhealthy behaviours. Compared with people without unhealthy behaviours, those with three unhealthy behaviours had a 2.5 -fold increased hazard of disability. Among several potential mediators, chronic conditions, and, to a lesser extent, depressive symptoms, trauma, and body mass index partially explained this association.

\section{What this study adds}

Previous research has shown an increased risk of disability in physically inactive people, ${ }^{19-22}$ those with an unhealthy diet, ${ }^{23-25}$ current smokers, ${ }^{192} 2627$ alcohol abstainers, ${ }^{192122} 28$ and heavy alcohol drinkers. ${ }^{21}$ However, not all studies took into account multiple behaviours simultaneously. Thus, confounding cannot be ruled out as a potential explanation because unhealthy behaviours are known to cluster. ${ }^{5}$ For instance, one study showed that the inverse association between moderate alcohol consumption and incident limitation of mobility was considerably attenuated after adjustment for education, income, body mass index, and other lifestyle variables such as smoking and physical activity. ${ }^{28}$ In our study, physical inactivity, low consumption of fruit and vegetables, and smoking were associated with disability and remained associated in models in which all unhealthy behaviours were included simultaneously. Our results thus suggest independent associations for three of the four behaviours considered.

Moreover, apart from notable exceptions, most studies have examined health behaviours separately and not their combined effect. One study examined the combined effect of smoking, alcohol consumption, physical activity, and sleep on the risk of walking and bathing disability in people aged 60 years and over in Taiwan. ${ }^{21}$ Not smoking, moderate alcohol consumption, regular exercise, and sleeping six to eight hours a day were inversely and independently associated with the risk of disability. Another study examined the association of smoking, alcohol intake, physical activity, and diet with impairment of mobility in obese and non-obese people aged 70-79 years in the United States. ${ }^{29}$ Current and former smoking, former alcohol intake, low physical activity, and an unhealthy diet were risk factors for incident limitation of mobility in non-obese older people, whereas in obese people the association was evident only for low physical activity. In agreement with our findings, both studies showed that behaviours had cumulative effects and that the risk of disability increased progressively with the number of unhealthy behaviours. A third study also showed, in both men and women, a combined effect of smoking, body mass index, and physical activity on the risk of disability in basic activities of daily living. ${ }^{30}$

Disability is a progressive process, and declining function is likely to influence health behaviours and therefore contribute to some of the observed associations between unhealthy behaviours and disability (reverse causation), particularly for physical activity and diet. An important contribution of our study was to examine the association between unhealthy behaviours at study inception and incident disability after exclusion of the participants who developed disability in the first four years of follow-up (about $30 \%$ of all incident cases). The results of these analyses, discussed below for each of the behaviours, yielded findings largely consistent with our main analyses, thus ruling out reverse causation as an explanation of our findings. Only one previous study, based on a total of 6.5 years of follow-up, considered reverse causation by excluding participants who developed disability in the first two years. ${ }^{29}$ Our study, which had a longer follow-up and allowed us to exclude participants who developed disability in the first four years, provides more convincing evidence that the association between unhealthy behaviours and disability does not result from reverse causation.

Our findings are in line with studies on mortality, ${ }^{12-15} 1718$ chronic diseases, ${ }^{8}$ or cognition, ${ }^{9}$ showing unhealthy behaviours to have cumulative effects. These findings have important public health implications, as these behaviours are potentially modifiable, and interventions aimed at promoting a healthy lifestyle may help to prevent the onset of disability. In addition, our findings suggest that interventions targeting multiple behaviours may carry greater benefit than simpler interventions.

\section{Possible explanations}

In our study, low or intermediate physical activity was strongly associated with disability. This association may partly reflect the fact that declining function preceding disability could affect physical activity (reverse causation); excluding participants disabled at baseline may not be sufficient to remove this effect. In analyses excluding the first years of follow-up, the association of physical activity with disability was very similar, suggesting that reverse causation does not fully account for this association. Regarding diet, previous analyses based on the Bordeaux-3C study showed that adherence to a Mediterranean-type diet was associated with the risk of disability in basic or instrumental activities of daily living in women but not in men, although reasons for this difference were unclear. ${ }^{23}$ In our study, consumption of fruit and vegetables was associated with disability in both sexes, even in analyses excluding the first years of follow-up. Regarding smoking, participants who quit smoking more than 15 years before study inception did not have an increased hazard of disability compared with never smokers, whereas more recent ex-smokers and current smokers had an increased hazard of disability that persisted in analyses excluding the first years of follow-up.

Our results for alcohol consumption were less robust. Former drinkers represented a small proportion of the sample (2.2\%) and had a 50\% greater hazard of disability; this association was no longer statistically significant after adjustment for other behaviours. In older populations, it has been suggested that poor health increases the likelihood of not drinking alcohol. However, in our analysis this association remained present and strengthened in analyses excluding the first years of follow-up, suggesting that it was not fully explained by former drinkers developing disability soon after baseline. Abstainers and heavy drinkers did not have an increased hazard of disability. 
Participants reporting heavy drinking at baseline probably represent a selected group who survived until at least 65 years despite heavy drinking.

The most important contributors to the association between unhealthy behaviours and disability were chronic conditions (especially dyspnoea), depressive symptoms, trauma, and higher body mass index. Dyspnoea is a hallmark of heart failure, which is a major cause of disability in older people. Body mass index is an important risk factor for disability, ${ }^{19} 294748$ and the prevalence of obesity increases with the number of unhealthy behaviours. ${ }^{7}$ A previous study also showed that body mass index partially explained the association between alcohol consumption and impairment of mobility. ${ }^{28}$ Cognitive function and cardiovascular disease and its risk factors made modest contributions to the association in our study. For some of these covariates (such as hypertension), results can be explained by a lack of strong associations with health behaviours. Although we considered these covariates measured over the follow-up to mediate the association between unhealthy behaviours measured at baseline and disability, some of the mediators may have a bidirectional association with behaviours over the follow-up.

\section{Strengths and weaknesses of study}

Our findings need to be considered in the light of some limitations. Firstly, disability was self reported, even though the validity of this measure has been well established with respect to objective measures of physical and cognitive function. ${ }^{49-51}$ Secondly, the main analyses did not take into account the possibility that some people recover from disability. However, analyses excluding these people did not change our results. Thirdly, time to event analyses do not allow categorical outcomes, leading us to dichotomise the hierarchical indicator of disability; analyses based on multinomial logistic regression showed that risk increased with increasing levels of disability and with the number of unhealthy behaviours. Fourthly, health behaviours were assessed at baseline and we were not able to take into account changes before baseline or over the follow-up. Owing to the potential for reverse causation, time dependent health behaviours may in fact lead to overestimate some of the associations. In addition, health behaviours are relatively stable over time in older people, except in those with serious illness or just before death. ${ }^{52}{ }^{53}$ Fifthly, health behaviours were assessed using relatively simple questions and a risk of some misclassification exists; this, however, would bias the examined associations towards the null. We defined behaviours a priori, on the basis of previous studies; sensitivity analyses that assessed alternative definitions yielded results largely consistent with our main findings. Sixthly, participants excluded from the analyses were older at baseline but not significantly different from other participants except for alcohol consumption and fruit and vegetable intake. Although we probably underestimated the absolute risk of disability, this would be unlikely to bias the estimate of the association between unhealthy behaviours and disability. Seventhly, we have probably underestimated the role of some mediators, particularly stroke, because participants with severe stroke during the follow-up may have dropped out of the study. Finally, at baseline, participants were community dwelling, well functioning older adults and therefore in better health than people who did not participate. Although this may lead to underestimation of the incidence of disability, provided that follow-up is adequate, the association between baseline exposures and the incidence of an outcome is unlikely to be biased. ${ }^{54}$ Selection bias may, however, have an effect on estimation of the role of mediators by biasing their baseline association with unhealthy behaviours ${ }^{55}$; our use of time dependent covariates attenuates this concern.

This study's main strengths include its large size and length of follow-up with regular assessments of disability. The main outcome is a hierarchical indicator of disability that combines information from three disability scales ordered in a hierarchy that better describes the evolution of disability. ${ }^{35}$ In addition, we used a statistical method that takes interval censoring and competing risk of death into account. Finally, associations between unhealthy behaviours and disability remained present after exclusion of the first years of follow-up, suggesting that the associations of disability with low physical activity and poor diet were not explained by disability occurring close to the assessments of these behaviours. For people who quit smoking recently (defined as stopping smoking in the 15 years before the baseline examination), the observed hazard of disability also suggests that reverse causation did not contribute to the association between smoking and disability.

\section{Conclusion}

This cohort study among French older adults suggests that an unhealthy lifestyle, characterised by physical inactivity, an unhealthy diet, and smoking, is associated with greater hazard of disability, which increased progressively with the number of unhealthy behaviours. Health behaviours are potentially modifiable, and our findings may be useful for policy makers regarding the potential benefit of multi-behaviour interventions compared with single behaviour interventions.

We thank Célia Touraine for her help in implementing interval censored analyses.

Contributors: FA, SS, AS-M, and AE designed the study. FA did the statistical analyses. AD provided assistance with the statistical analyses. FA and AE drafted the manuscript. All authors critically revised the manuscript for important intellectual content. CT obtained funding and supervised the study. FA and $\mathrm{AE}$ are the guarantors.

Funding: The $3 \mathrm{C}$ study is conducted under a partnership agreement between the Institut National de la Santé et de la Recherche Médicale (INSERM), the Victor Segalen-Bordeaux II University, and the Sanofi-Synthélabo Company. The Fondation pour la Recherche Médicale funded the preparation and initiation of the study. The $3 \mathrm{C}$ study is also supported by the Caisse Nationale Maladie des Travailleurs Salariés, Direction Générale de la Santé, Conseils Régionaux of Bourgogne, Fondation de France, Ministry of Research-INSERM Program, "Cohortes et collections de données biologiques," Mutuelle Générale de l'Education Nationale, Institut de la Longévité, Conseil Général de la Côte d'or, and Fondation Plan Alzheimer. This research was also funded by Institut national de prévention et d'éducation pour la santé (INPES,

$\left.\mathrm{N}^{\circ} 063 / 11-\mathrm{DAS}\right)$. $\mathrm{FA}$ is the recipient of a doctoral grant from the Ministère de l'Enseignement Supérieur et de la Recherche, Paris, France, and the EHESP (Ecole des Hautes Etudes en Santé Publique), Rennes, France. The sponsors had no role in study design, data collection, data analysis, data interpretation, the writing of the report, or the decision to submit the paper for publication.

Competing interests: All authors have completed the ICMJE uniform disclosure form at www.icmje.org/coi_disclosure.pdf (available on request from the corresponding author) and declare: $\mathrm{CT}$ has received research support from Agence Nationale de la Recherche (ANR) and Fondation Plan Alzheimer for the Three-City Study; CT has served on scientific advisory boards for Merck Sharp and Dohme and Fondation Plan Alzheimer and has received speaker honorariums from Abbott and Fondation Recherche HTA; no relationships with other companies that might have an interest in the submitted work in the previous three years; 


\section{What is already known on this topic}

Some evidence shows that unhealthy behaviours are associated with an increased risk of disability in older people, but their independent contribution to disability remains unclear

Few studies have examined the combined association of unhealthy behaviours with disability, and reverse causation may have contributed to the association in previous studies

The pathways involved in the association between unhealthy behaviours and disability are poorly understood

\section{What this study adds}

Low/intermediate physical activity, a diet poor in fruit and vegetables, and smoking, were independently associated with an increased hazard of disability

The hazard of disability increased progressively with the number of unhealthy behaviours; people with three unhealthy behaviours had more than a twofold increased hazard of disability

Similar conclusions were reached in analyses restricted to participants who developed disability more than four years after the assessment of behaviours, ruling out reverse causation as a major explanation

Chronic conditions, and to a lesser extent depressive symptoms, trauma, and body mass index, partially explained this association

no other non-financial interests that may be relevant to the submitted work.

Ethical approval: The study protocol was approved by the ethical committee of the Kremlin-Bicêtre University-Hospital (France), and all participants gave written informed consent.

Data sharing: No additional data available.

1 Fried LP, Ferrucci L, Darer J, Williamson JD, Anderson G. Untangling the concepts of disability, frailty, and comorbidity: implications for improved targeting and care. J Gerontol A Biol Sci Med Sci 2004;59:255-63.

2 Peres K, Helmer C, Letenneur L, Jacqmin-Gadda H, Barberger-Gateau P. Ten-year change in disability prevalence and related factors in two generations of French elderly community dwellers: data from the PAQUID study. Aging Clin Exp Res 2005;17:229-35.

3 Donald IP, Foy C, Jagger C. Trends in disability prevalence over 10 years in older people living in Gloucestershire. Age Ageing 2010;39:337-42.

4 Duée M, Rebillard C. La dépendance des personnes âgées: une projection en 2040. Données sociales_La société française 2006; édition 2006:613-9.

5 Poortinga W. The prevalence and clustering of four major lifestyle risk factors in an English adult population. Prev Med 2007:44:124-8.

6 Pronk NP, Anderson LH, Crain AL, Martinson BC, O'Connor PJ, Sherwood NE, et al. Meeting recommendations for multiple healthy lifestyle factors: prevalence, clustering, and predictors among adolescent, adult, and senior health plan members. Am J Prev Med 2004:27(2 suppl):25-33.

7 Harrington J, Perry IJ, Lutomski J, Fitzgerald AP, Shiely F, McGee H, et al. Living longer and feeling better: healthy lifestyle, self-rated health, obesity and depression in Ireland. Eur J Public Health 2010;20:91-5.

8 Ford ES, Bergmann MM, Kroger J, Schienkiewitz A, Weikert C, Boeing H. Healthy living is the best revenge: findings from the European Prospective Investigation Into Cance and Nutrition-Potsdam study. Arch Intern Med 2009;169:1355-62.

9 Sabia S, Nabi H, Kivimaki M, Shipley MJ, Marmot MG, Singh-Manoux A. Health behaviors from early to late midlife as predictors of cognitive function: the Whitehall II study. $A m \mathrm{~J}$ Epidemiol 2009;170:428-37.

10 Chiuve SE, Rexrode KM, Spiegelman D, Logroscino G, Manson JE, Rimm EB. Primary prevention of stroke by healthy lifestyle. Circulation 2008;118:947-954.

11 Chiuve SE, Fung TT, Rexrode KM, Spiegelman D, Manson JE, Stampfer MJ, et al. Adherence to a low-risk, healthy lifestyle and risk of sudden cardiac death among women. JAMA 2011;306:62-9.

12 Hamer M, Bates CJ, Mishra GD. Multiple health behaviors and mortality risk in older adults. J Am Geriatr Soc 2011;59:370-2.

13 Khaw KT, Wareham N, Bingham S, Welch A, Luben R, Day N. Combined impact of health behaviours and mortality in men and women: the EPIC-Norfolk prospective population study. PLoS Med 2008;5:e12.

14 Kvaavik E, Batty GD, Ursin G, Huxley R, Gale CR. Influence of individual and combined health behaviors on total and cause-specific mortality in men and women: the United Kingdom health and lifestyle survey. Arch Intern Med 2010;170:711-8.

15 Knoops KT, de Groot LC, Kromhout D, Perrin AE, Moreiras-Varela O, Menotti A, et al. Mediterranean diet, lifestyle factors, and 10-year mortality in elderly European men and women: the HALE project. JAMA 2004:292:1433-9.

16 Loef $\mathrm{M}$, Walach $\mathrm{H}$. The combined effects of healthy lifestyle behaviors on all cause mortality: a systematic review and meta-analysis. Prev Med 2012;55:163-70.

17 Van Dam RM, Li T, Spiegelman D, Franco OH, Hu FB. Combined impact of lifestyle factors on mortality: prospective cohort study in US women. BMJ 2008;337:a1440.

18 Van den Brandt PA. The impact of a Mediterranean diet and healthy lifestyle on premature mortality in men and women. Am J Clin Nutr 2011:94:913-20.

19 LaCroix AZ, Guralnik JM, Berkman LF, Wallace RB, Satterfield S. Maintaining mobility in late life: II. Smoking, alcohol consumption, physical activity, and body mass index. Am J Epidemiol 1993;137:858-69.

20 Landi F, Russo A, Barillaro C, Cesari M, Pahor M, Danese P, et al. Physical activity and risk of cognitive impairment among older persons living in the community. Aging Clin Exp Res 2007:19:410-6.

21 Liao WC, Li CR, Lin YC, Wang CC, Chen YJ, Yen CH, et al. Healthy behaviors and onset of functional disability in older adults: results of a national longitudinal study. J Am Geriatr Soc 2011;59:200-6

22 Wang L, van Belle G., Kukull WB, Larson EB. Predictors of functional change: a longitudina study of nondemented people aged 65 and older. J Am Geriatr Soc 2002;50:1525-34.

23 Feart C, Peres K, Samieri C, Letenneur L, Dartigues JF, Barberger-Gateau P. Adherence to a Mediterranean diet and onset of disability in older persons. Eur J Epidemiol 2011;26:747-56
24 Houston DK, Stevens J, Cai J, Haines PS. Dairy, fruit, and vegetable intakes and functional limitations and disability in a biracial cohort: the Atherosclerosis Risk in Communities Study. Am J Clin Nutr 2005;81:515-22.

25 Vercambre MN, Boutron-Ruault MC, Ritchie K, Clavel-Chapelon F, Berr C. Long-term association of food and nutrient intakes with cognitive and functional decline: a 13-year follow-up study of elderly French women. Br J Nutr 2009;102:419-27.

26 Chakravarty EF, Hubert HB, Krishnan E, Bruce BB, Lingala VB, Fries JF. Lifestyle risk factors predict disability and death in healthy aging adults. Am J Med 2012;125:190-7.

27 Tsubota-Utsugi M, Ito-Sato R, Onkubo T, Kikuya M, Asayama K, Metoki H, et al. Health behaviors as predictors for declines in higher-level functional capacity in older adults: the Ohasama study. J Am Geriatr Soc 2011;59:1993-2000.

28 Maraldi C, Harris TB, Newman AB, Kritchevsky SB, Pahor M, Koster A, et al. Moderate alcohol intake and risk of functional decline: the Health, Aging, and Body Composition study. J Am Geriatr Soc 2009;57:1767-75.

29 Koster A, Penninx BW, Newman AB, Visser M, van Gool CH, Harris TB, et al. Lifestyle factors and incident mobility limitation in obese and non-obese older adults. Obesity (Silver Spring) 2007;15:3122-32

30 Vita AJ, Terry RB, Hubert HB, Fries JF. Aging, health risks, and cumulative disability. N Engl J Med 1998;338:1035-41.

$313 \mathrm{C}$ Study Group. Vascular factors and risk of dementia: design of the Three-City Study and baseline characteristics of the study population. Neuroepidemiology 2003;22:316-25.

32 Rosow I, Breslau N. A Guttman health scale for the aged. J Gerontol 1966;21:556-9.

33 Lawton MP, Brody EM. Assessment of older people: self-maintaining and instrumental activities of daily living. Gerontologist 1969;9:179-86

34 Katz S, Ford AB, Moskowitz RW, Jackson BA, Jaffe MW. Studies of illness in the aged: the index of ADL: a standardized measure of biological and psychological function. JAMA 1963;185:914-9.

35 Barberger-Gateau P, Rainville C, Letenneur L, Dartigues JF. A hierarchical model of domains of disablement in the elderly: a longitudinal approach. Disabil Rehabil 2000;22:308-17.

36 Peres K, Verret C, Alioum A, Barberger-Gateau P. The disablement process: factors associated with progression of disability and recovery in French elderly people. Disabil Rehabil 2005;27:263-76.

37 Andrews G, Jenkins R. Management of mental disorders (UK edition). World Health Organization Collaborating Centre for Mental Health and Substance Abuse, 1999.

38 Sabia S, Singh-Manoux A, Hagger-Johnson G, Cambois E, Brunner EJ, Kivimaki M. Influence of individual and combined healthy behaviours on successful aging. CMAJ 2012;184:1985-92.

39 Rosso AL, Eaton CB, Wallace R, Gold R, Stefanick ML, Ockene JK, et al. Geriatric syndromes and incident disability in older women: results from the Women's Health Initiative Observational Study. J Am Geriatr Soc 2013;61:371-9.

40 Wong E, Stevenson C, Backholer K, Mannan H, Pasupathi K, Hodge A, et al. Adiposity measures as predictors of long-term physical disability. Ann Epidemiol 2012;22:710-6.

41 Ling SM, Xue QL, Simonsick EM, Tian J, Bandeen-Roche K, Fried LP et al. Transitions to mobility difficulty associated with lower extremity osteoarthritis in high functioning older women: Iongitudinal data from the Women's Health and Aging Study II. Arthritis Rheum 2006;55:256-63.

42 Leibson CL, Tosteson AN, Gabriel SE, Ransom JE, Melton LJ. Mortality, disability, and nursing home use for persons with and without hip fracture: a population-based study. $J$ Am Geriatr Soc 2002:50:1644-50.

43 Hewitt M, Rowland JH, Yancik R. Cancer survivors in the United States: age, health, and disability. J Gerontol A Biol Sci Med Sci 2003;58:82-91.

44 Fuhrer R, Rouillon F. La version française de l'échelle CES-D (Center for Epidemiologic Studies-depression scale): description et traduction de l'échelle d'autoévaluation. Psychiatrie et psychobiologie 1989;4:163-6.

45 Blachier M, Dauvilliers Y, Jaussent I, Helmer C, Ritchie K, Jouven X, et al. Excessive daytime sleepiness and vascular events: the Three City Study. Ann Neurol 2012;71:661-7.

46 Joly P, Commenges D, Helmer C, Letenneur L. A penalized likelihood approach for an illness-death model with interval-censored data: application to age-specific incidence of dementia. Biostatistics 2002;3:433-43.

47 Koster A, Patel KV, Visser M, van Eijk JT, Kanaya AM, de Rekeneire N, et al. Joint effects of adiposity and physical activity on incident mobility limitation in older adults. J Am Geriatr Soc 2008;56:636-43.

48 Larrieu S, Peres K, Letenneur L, Berr C, Dartigues JF, Ritchie K, et al. Relationship between body mass index and different domains of disability in older persons: the $3 C$ study. Int J Obes Relat Metab Disord 2004;28:1555-60.

49 Fried LP, Young Y, Rubin G, Bandeen-Roche K. Self-reported preclinical disability identifies older women with early declines in performance and early disease. J Clin Epidemiol 2001;54:889-901.

50 Young Y, Boyd CM, Guralnik JM, Fried LP. Does self-reported function correspond to objective measures of functional impairment? J Am Med Dir Assoc 2010;11:645-53. 
51 Barberger-Gateau P, Fabrigoule C, Amieva H, Helmer C, Dartigues JF. The disablement process: a conceptual framework for dementia-associated disability. Dement Geriatr Cogn Disord 2002;13:60-6.

52 Buck B, Frosini F. Clustering of unhealthy behaviours over time: implications for policy and practice. King's Fund, 2012 (available at www.kingsfund.org.uk/publications/unhealthy behaviours.html).

53 Glynn RJ, Bouchard GR, LoCastro JS, Laird NM. Aging and generational effects on drinking behaviors in men: results from the normative aging study. Am J Public Health drinking behaviors

54 Criqui MH. Response bias and risk ratios in epidemiologic studies. Am J Epidemio 1979;109:394-9.

55 Morimoto LM, White E, Newcomb PA. Selection bias in the assessment of gene-environment interaction in case-control studies. Am J Epidemiol 2003;158:259-63.

\section{Accepted: 25 June 2013}

Cite this as: BMJ 2013;347:f4240

This is an Open Access article distributed in accordance with the Creative Commons Attribution Non Commercial (CC BY-NC 3.0) license, which permits others to distribute, remix, adapt, build upon this work non-commercially, and license their derivative works on different terms, provided the original work is properly cited and the use is non-commercial. See: http://creativecommons.org/licenses/by-nc/3.0/. 


\section{Tables}

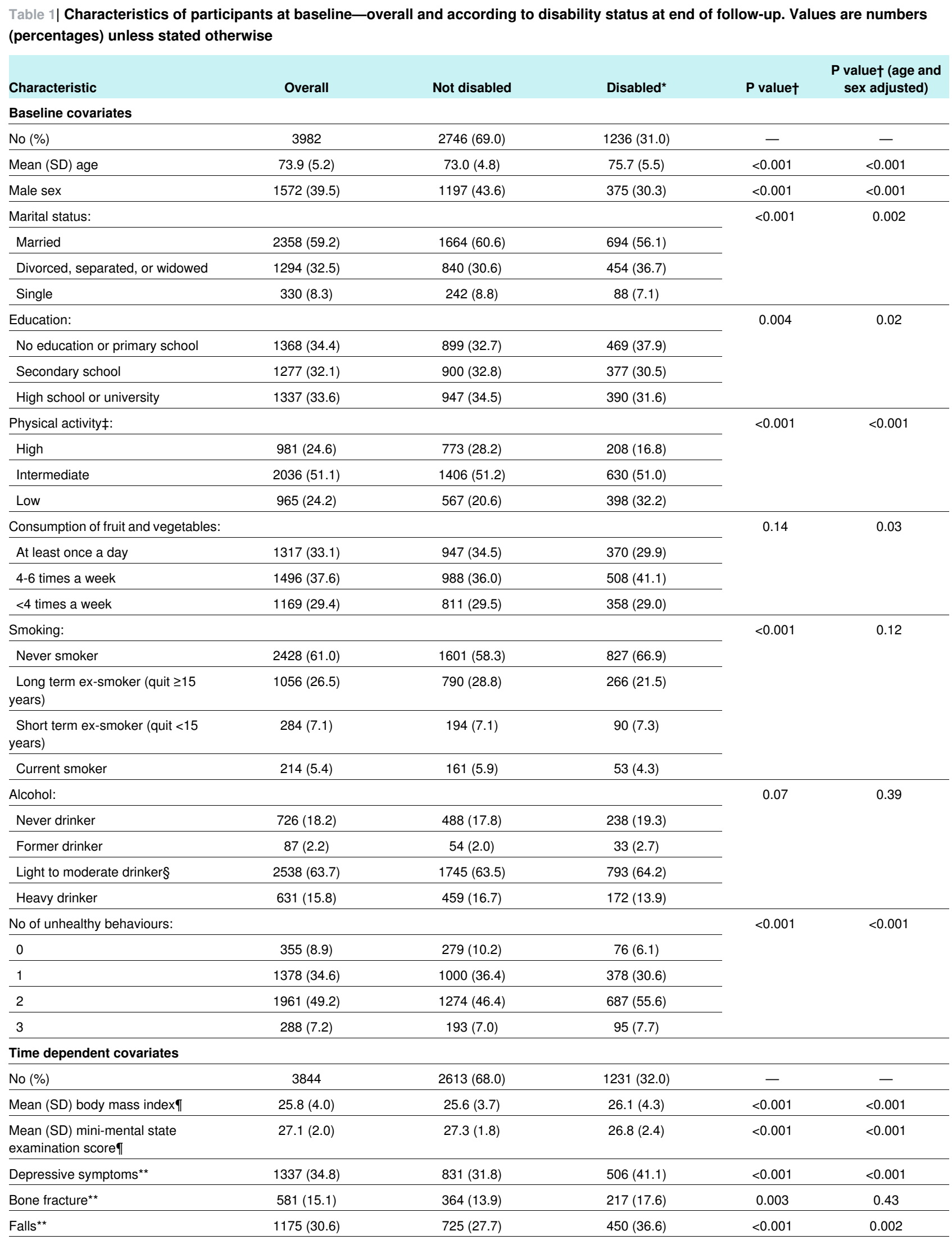


Table 1 (continued)

\begin{tabular}{|c|c|c|c|c|c|}
\hline Characteristic & Overall & Not disabled & Disabled $^{*}$ & P value† & $\begin{array}{l}\text { P valuet (age and } \\
\text { sex adjusted) }\end{array}$ \\
\hline Diabetes $^{\star *}$ & $506(13.2)$ & $335(12.8)$ & $171(13.9)$ & 0.36 & 0.03 \\
\hline Parkinson's disease ${ }^{\star \star}$ & $77(2.0)$ & $34(1.3)$ & $43(3.5)$ & $<0.001$ & $<0.001$ \\
\hline Vision difficulties ${ }^{* *}$ & $668(17.4)$ & $392(15.0)$ & $276(22.4)$ & $<0.001$ & $<0.001$ \\
\hline Deafness $^{\star *}$ & $803(20.9)$ & $481(18.4)$ & $322(26.2)$ & $<0.001$ & $<0.001$ \\
\hline Dyspnoea** & $876(22.8)$ & $469(17.9)$ & $407(33.1)$ & $<0.001$ & $<0.001$ \\
\hline NSAIDs for joint pain ${ }^{* *}$ & $907(23.6)$ & $598(22.9)$ & $309(25.1)$ & 0.13 & 0.70 \\
\hline Cancer** & $585(15.2)$ & $411(15.7)$ & $174(14.1)$ & 0.20 & 0.48 \\
\hline Stroke** & $226(5.9)$ & $129(4.9)$ & $97(7.9)$ & $<0.001$ & $<0.001$ \\
\hline $\begin{array}{l}\text { Coronary heart disease or lower limb } \\
\text { arteritis }{ }^{\star *}\end{array}$ & $697(18.1)$ & $445(17.0)$ & $252(20.5)$ & 0.01 & 0.002 \\
\hline Hypertension ${ }^{\star *}$ & $3369(87.6)$ & $2275(87.1)$ & $1094(88.9)$ & 0.11 & 0.46 \\
\hline Hypercholesterolaemia** & $1739(45.2)$ & $1213(46.4)$ & $526(42.7)$ & 0.03 & 0.09 \\
\hline
\end{tabular}

NSAID=non-steroidal anti-inflammatory drug.

*Dependent for Rosow and instrumental activities of daily living scales \pm basic activities of daily living scale (dichotomised hierarchical indicator of disability). †Analysis of covariance for continuous variables and Mantel-Haenszel $x^{2}$ test for categorical variables.

$\ddagger$ High=walking more than one hour a day and exercising more than once a week; low=walking less than one hour a day and exercising less than once a week; intermediate=all others.

\$1-21 drinks a week in men; 1-14 drinks a week in women.

IMean of all measures taken during follow-up.

${ }^{* *}$ At least one report over follow-up. 


\begin{tabular}{|c|c|c|c|c|c|c|c|c|}
\hline \multirow[b]{2}{*}{ Characteristic } & \multicolumn{3}{|c|}{ Model $1^{*}$} & \multicolumn{3}{|c|}{ Model $2 \uparrow$} & \multicolumn{2}{|c|}{ Model 3† } \\
\hline & HR (95\% Cl) & $P$ value & $P$ value & HR (95\% Cl) & $P$ value & $P$ value & $\mathrm{HR}(95 \% \mathrm{Cl})$ & $P$ value \\
\hline \multicolumn{9}{|l|}{ Physical activitył: } \\
\hline High & 1.00 (reference) & - & & 1.00 (reference) & - & & - & - \\
\hline Intermediate & $1.58(1.35$ to 1.86$)$ & $<0.001$ & & $1.53(1.31$ to 1.78$)$ & $<0.001$ & & - & - \\
\hline Low & 2.16 (1.82 to 2.56$)$ & $<0.001$ & $<0.001 \rrbracket$ & 2.10 (1.77 to 2.48$)$ & $<0.001$ & $<0.001 \rrbracket$ & - & - \\
\hline Low or intermediate $v$ high & 1.76 (1.51 to 2.05$)$ & $<0.001$ & & - & - & & $\begin{array}{c}1.72(1.48 \text { to } \\
2.00)\end{array}$ & $<0.001$ \\
\hline \multicolumn{9}{|l|}{$\begin{array}{l}\text { Consumption of fruits and } \\
\text { vegetables: }\end{array}$} \\
\hline At least once a day & 1.00 (reference) & - & & 1.00 (reference) & - & & - & - \\
\hline 4-6 times a week & $1.27(1.11$ to 1.45$)$ & $<0.001$ & & 1.27 (1.11 to 1.45$)$ & 0.001 & & 一 & - \\
\hline$<4$ times a week & 1.31 (1.13 to 1.52$)$ & $<0.001$ & $<0.001 \rrbracket$ & 1.25 (1.08 to 1.44$)$ & 0.003 & $0.003 \rrbracket$ & 一 & - \\
\hline $\begin{array}{l}\text { Less than once a day } v \text { at } \\
\text { least once a day }\end{array}$ & $1.29(1.14$ to 1.45$)$ & $<0.001$ & & - & - & & $\begin{array}{c}1.24(1.10 \text { to } \\
1.41)\end{array}$ & 0.001 \\
\hline \multicolumn{9}{|l|}{ Smoking: } \\
\hline Never smoker & 1.00 (reference) & - & & 1.00 (reference) & - & & - & - \\
\hline $\begin{array}{l}\text { Long term ex-smoker (quit } \\
\geq 15 \text { years) }\end{array}$ & $1.02(0.88$ to 1.19$)$ & 0.78 & & 1.05 (0.90 to 1.24$)$ & 0.51 & & - & - \\
\hline $\begin{array}{l}\text { Short term ex-smoker (quit } \\
<15 \text { years) }\end{array}$ & $1.42(1.14$ to 1.76$)$ & 0.002 & & $1.44(1.15$ to 1.80$)$ & 0.001 & & - & - \\
\hline Current smoker & 1.13 (0.85 to 1.51$)$ & 0.39 & 0.02 & 1.14 (0.85 to 1.53$)$ & 0.37 & 0.02 & 一 & - \\
\hline $\begin{array}{l}\text { Current smoker or short term } \\
\text { ex-smoker } v \text { never smoker } \\
\text { or long term ex-smoker }\end{array}$ & 1.29 (1.09 to 1.54$)$ & 0.004 & & - & - & & $\begin{array}{c}1.26(1.05 \text { to } \\
1.50)\end{array}$ & 0.01 \\
\hline \multicolumn{9}{|l|}{ Alcohol: } \\
\hline Never drinker & 1.05 (0.90 to 1.22$)$ & 0.53 & & $1.04(0.89$ to 1.20$)$ & 0.64 & & - & - \\
\hline Former drinker & 1.49 (1.05 to 2.12$)$ & 0.03 & & 1.38 (0.96 to 1.97$)$ & 0.08 & & - & - \\
\hline Light to moderate drinker§ & 1.00 (reference) & 一 & & 1.00 (reference) & 一 & & - & 一 \\
\hline Heavy drinker & $0.98(0.83$ to 1.16$)$ & 0.80 & 0.18 & $0.93(0.79$ to 1.10$)$ & 0.40 & 0.26 & - & - \\
\hline $\begin{array}{l}\text { Never, former, or heavy } \\
\text { drinker } v \text { light to moderate } \\
\text { drinker }\end{array}$ & 1.04 (0.93 to 1.17$)$ & 0.49 & & - & - & & $\begin{array}{c}1.01(0.90 \text { to } \\
1.13)\end{array}$ & 0.84 \\
\hline \multicolumn{9}{|l|}{$\mathrm{HR}=$ hazard ratio. } \\
\hline \multicolumn{9}{|c|}{ *Adjusted for sex, marital status, their interaction, and education. } \\
\hline \multicolumn{9}{|c|}{ †Adjusted for sex, marital status, their interaction, education, and other behaviours. } \\
\hline \multicolumn{9}{|c|}{$\begin{array}{l}\text { ¥High=walking more than one hour a day and exercising more than once a week; low=walking less than one hour a day and exercising less than once a week; } \\
\text { intermediate=all others. }\end{array}$} \\
\hline \multicolumn{9}{|c|}{$\S 1-21$ drinks a week in men; $1-14$ drinks a week in women. } \\
\hline IP value for trend. & & & & & & & & \\
\hline
\end{tabular}


Table 3 | . Hazard ratio of disability according to physical activity, consumption of fruit and vegetables, smoking, alcohol drinking, and number of unhealthy behaviours, excluding first four years of follow-up $(n=2584)$

\begin{tabular}{|c|c|c|c|c|c|c|c|c|c|}
\hline \multirow[b]{2}{*}{ Characteristics } & \multirow{2}{*}{$\begin{array}{c}\text { Events } \\
(\mathrm{n} / \mathrm{N})\end{array}$} & \multicolumn{2}{|c|}{ Model 1* } & \multirow[b]{2}{*}{$P$ value } & \multicolumn{2}{|c|}{ Model 2† } & \multirow[b]{2}{*}{ P value } & \multicolumn{2}{|c|}{ Model 3† } \\
\hline & & HR (95\% Cl) & $P$ value & & HR (95\% Cl) & $P$ value & & HR (95\% Cl) & $P$ value \\
\hline \multicolumn{10}{|l|}{ Physical activitył: } \\
\hline High & $180 / 731$ & 1.00 (reference) & & & 1.00 (reference) & & & - & - \\
\hline Intermediate & $454 / 1295$ & $1.59(1.34$ to 1.90$)$ & $<0.001$ & & $\begin{array}{c}1.54(1.29 \text { to } \\
1.84)\end{array}$ & $<0.001$ & & - & - \\
\hline Low & $256 / 558$ & $2.14(1.77$ to 2.60$)$ & $<0.001$ & $<0.001 \rrbracket$ & $\begin{array}{c}2.09(1.71 \text { to } \\
2.54)\end{array}$ & $<0.001$ & $<0.001$ đ & - & - \\
\hline $\begin{array}{l}\text { Low or intermediate } v \\
\text { high }\end{array}$ & & 1.76 (1.49 to 2.08$)$ & $<0.001$ & & - & - & & $\begin{array}{c}1.71(1.45 \text { to } \\
2.03)\end{array}$ & $<0.001$ \\
\hline \multicolumn{10}{|l|}{$\begin{array}{l}\text { Consumption of fruit and } \\
\text { vegetables: }\end{array}$} \\
\hline At least once a day & $274 / 883$ & 1.00 (reference) & - & & 1.00 (reference) & - & & - & - \\
\hline 4-6 times a week & $374 / 999$ & $1.33(1.14$ to 1.56$)$ & $<0.001$ & & $\begin{array}{c}1.31(1.12 \text { to } \\
1.54)\end{array}$ & 0.001 & & - & - \\
\hline$<4$ times a week & $242 / 702$ & $1.34(1.13$ to 1.60$)$ & 0.001 & $<0.001$ đ & $\begin{array}{c}1.25(1.05 \text { to } \\
1.50)\end{array}$ & 0.01 & $0.01 \rrbracket$ & - & - \\
\hline $\begin{array}{l}\text { Less than once a day } \\
v \text { at least once a day }\end{array}$ & & $1.33(1.15$ to 1.54$)$ & $<0.001$ & & - & - & & $\begin{array}{c}1.27(1.10 \text { to } \\
1.47)\end{array}$ & 0.001 \\
\hline \multicolumn{10}{|l|}{ Smoking: } \\
\hline Never smoker & $585 / 1609$ & 1.00 (reference) & - & & 1.00 (reference) & - & & - & - \\
\hline $\begin{array}{l}\text { Long term ex-smoker } \\
\text { (quit } \geq 15 \text { years) }\end{array}$ & $195 / 657$ & 1.01 (0.85 to 1.19$)$ & 0.94 & & $\begin{array}{c}1.03(0.86 \text { to } \\
1.25)\end{array}$ & 0.72 & & - & - \\
\hline $\begin{array}{l}\text { Short term ex-smoker } \\
\text { (quit }<15 \text { years) }\end{array}$ & $68 / 184$ & 1.39 (1.08 to 1.79$)$ & 0.01 & & $\begin{array}{c}1.39(1.07 \text { to } \\
1.80)\end{array}$ & 0.01 & & - & - \\
\hline Current smoker & $42 / 134$ & $1.26(0.91$ to 1.73$)$ & 0.16 & 0.06 & $\begin{array}{c}1.25(0.90 \text { to } \\
1.74)\end{array}$ & 0.18 & 0.08 & - & - \\
\hline $\begin{array}{l}\text { Current smoker or } \\
\text { short term ex-smoker } v \\
\text { never smoker or long } \\
\text { term ex-smoker }\end{array}$ & & 1.34 (1.10 to 1.65$)$ & 0.01 & & - & - & & $\begin{array}{c}1.31(1.07 \text { to } \\
1.60)\end{array}$ & 0.01 \\
\hline \multicolumn{10}{|l|}{ Alcohol: } \\
\hline Never drinker & $172 / 486$ & 1.06 (0.89 to 1.26$)$ & 0.51 & & $\begin{array}{c}1.04(0.87 \text { to } \\
1.23)\end{array}$ & 0.70 & & - & - \\
\hline Former drinker & $22 / 51$ & 1.68 (1.08 to 2.64$)$ & 0.02 & & $\begin{array}{c}1.48(0.96 \text { to } \\
2.29)\end{array}$ & 0.08 & & - & - \\
\hline $\begin{array}{l}\text { Light to moderate } \\
\text { drinker§ }\end{array}$ & $573 / 1647$ & 1.00 (reference) & - & & 1.00 (reference) & - & & - & - \\
\hline Heavy drinker & $123 / 400$ & $0.96(0.78$ to 1.17$)$ & 0.66 & 0.15 & $\begin{array}{c}0.90(0.74 \text { to } \\
1.11)\end{array}$ & 0.32 & 0.23 & - & - \\
\hline $\begin{array}{l}\text { Never, former, or } \\
\text { heavy drinker } v \text { light to } \\
\text { moderate drinker }\end{array}$ & & 1.05 (0.91 to 1.20$)$ & 0.53 & & - & - & & $\begin{array}{c}1.00(0.92 \text { to } \\
1.09)\end{array}$ & 0.97 \\
\hline \multicolumn{10}{|l|}{$\begin{array}{l}\text { No of unhealthy } \\
\text { behaviours: }\end{array}$} \\
\hline 0 & $68 / 260$ & 1.00 (reference) & & & - & - & - & - & - \\
\hline 1 & $278 / 949$ & 1.26 (0.97 to 1.65$)$ & 0.08 & & - & - & - & - & - \\
\hline 2 & $474 / 1202$ & 1.89 (1.46 to 2.44$)$ & $<0.001$ & & - & - & - & - & - \\
\hline 3 & $70 / 173$ & 2.68 (1.91 to 3.76$)$ & $<0.001$ & $<0.001$ đ & - & - & - & - & - \\
\hline
\end{tabular}

HR=hazard ratio.

These analyses included 2584 participants (1602 (62.0\%) women), of whom 890 (613 (68.9\%) women) developed disability.

*Adjusted for sex, marital status, their interaction, and education.

†Adjusted for sex, marital status, their interaction, education, and other behaviours.

$\ddagger$ High=walking more than one hour a day and exercising more than once a week; low=walking less than one hour a day and exercising less than once a week;

intermediate $=$ all others 
Table 3 (continued)

\begin{tabular}{|c|c|c|c|c|c|c|c|c|c|}
\hline \multirow[b]{2}{*}{ Characteristics } & \multirow{2}{*}{$\begin{array}{c}\text { Events } \\
(n / N)\end{array}$} & \multicolumn{2}{|c|}{ Model $1^{*}$} & \multirow[b]{2}{*}{$P$ value } & \multicolumn{2}{|c|}{ Model $2 \dagger$} & \multirow[b]{2}{*}{$P$ value } & \multicolumn{2}{|c|}{ Model 3† } \\
\hline & & HR (95\% Cl) & $P$ value & & HR (95\% Cl) & $P$ value & & $\mathrm{HR}(95 \% \mathrm{Cl})$ & $P$ value \\
\hline
\end{tabular}


Table 4| Role of potential mediators in explaining association between number of unhealthy behaviours and disability

\begin{tabular}{|c|c|c|}
\hline Model & Hazard ratio $(95 \% \mathrm{Cl})^{\star}$ & Percentage reduction† \\
\hline Model $1 \ddagger$ & 1.40 (1.29 to 1.51$)$ & - \\
\hline Model $1+$ body mass index & 1.37 (1.26 to 1.49$)$ & 5.6 \\
\hline Model $1+$ cognitive function§ & $1.39(1.28$ to 1.50$)$ & 2.1 \\
\hline Model $1+$ depressive symptoms $\mathbb{T}$ & $1.36(1.25$ to 1.47$)$ & 9.0 \\
\hline Model $1+$ trauma $^{\star *}$ & $1.36(1.26$ to 1.48$)$ & 7.1 \\
\hline Model $1+$ chronic conditionst† & 1.34 (1.24 to 1.46$)$ & 11.5 \\
\hline Model $1+$ cardiovascular disease and its risk factorsł $¥$ & $1.38(1.27$ to 1.49$)$ & 3.9 \\
\hline Fully adjusted model§§§ & $1.26(1.16$ to 1.37$)$ & 30.5 \\
\hline
\end{tabular}

Analyses based on 3844 participants without missing values for any covariates.

${ }^{*}$ Per increase of one unhealthy behaviour.

$\dagger 100 \times\left(\beta_{\text {model } 1}-\beta_{\text {model }}\right) /\left(\beta_{\text {model } 1}\right)$.

$\ddagger$ Adjusted for sex, marital status, their interaction, and education.

$\S$ Mini-mental state examination score.

ICentre for Epidemiologic Studies depression scale.

${ }^{* *}$ Bone fracture, recurrent falls.

††Diabetes, Parkinson's disease, vision difficulties, deafness, dyspnoea, non-steroidal anti-inflammatory drug use for joint pain, cancer.

$\ddagger \ddagger S$ troke, coronary heart disease, lower limb arteritis, hypertension, hypercholesterolaemia.

$\S \S A$ ll covariates included in model. 


\section{Figure}

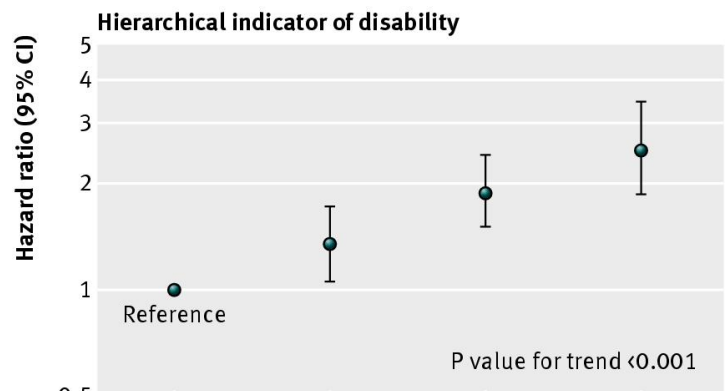

0.5

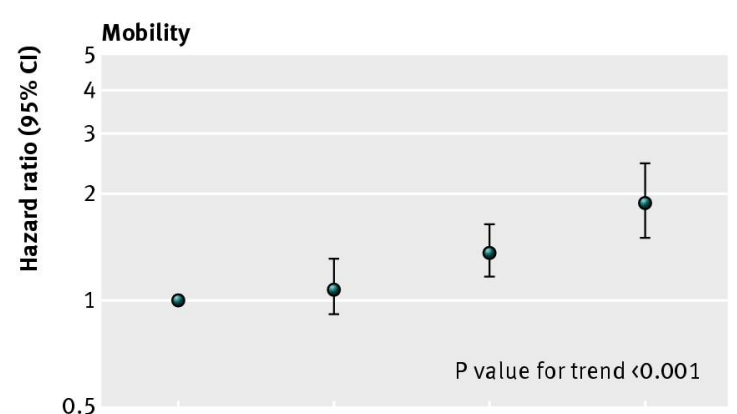

0.5

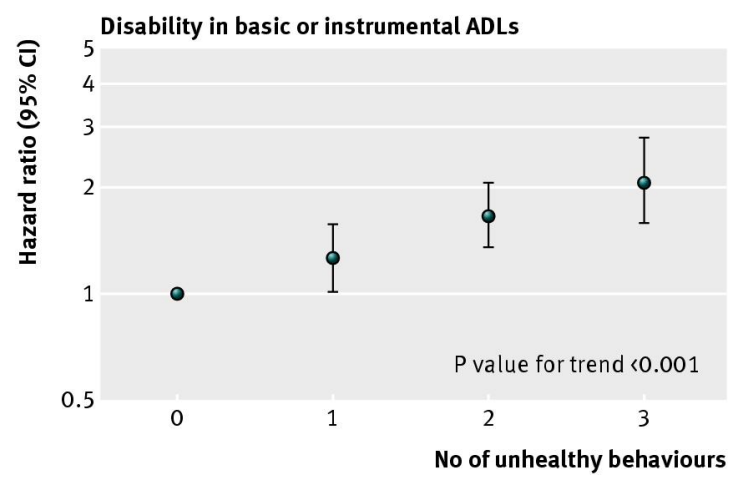

Hazard ratio of disability according to number of unhealthy behaviours (low/intermediate physical activity, consumption of fruit and vegetables less than once a day, and current smoking or short term ex-smoking): hierarchical indicator of disability (top panel), mobility (middle panel), and disability in basic or instrumental activities of daily living (ADLs) (bottom panel). Hazard ratios (95\% Cls) were computed using interval censored survival models with age as timescale and were adjusted for sex, marital status, their interaction, and education 


\section{SUPPLEMENTARY MATERIALS}

\section{Supplementary methods}

\section{Rosow and Breslau scale (mobility)}

\begin{tabular}{lc}
\hline Questions & Score \\
\hline A. Able to do heavy work around the house like washing windows, walls, or floors without help & 0 \\
Yes & 1 \\
No & \\
B. Able to walk between $500 \mathrm{~m}$ and $1 \mathrm{~km}$ without help & 0 \\
$\quad$ Yes & 1 \\
No & 0 \\
C. Able to walk up and down stairs to the second floor without help & 1 \\
$\quad$ Yes & \\
No &
\end{tabular}

\section{Lawton-Brody IADL scale}

\begin{tabular}{|c|c|}
\hline Questions & Score \\
\hline \multicolumn{2}{|l|}{ A. Ability to use telephone } \\
\hline 1. Operates telephone on own initiative; looks up and dials numbers, etc. & 0 \\
\hline 2. Dials a few well-known numbers & 0 \\
\hline 3. Answers telephone but does not dial & 0 \\
\hline 4. Does not use telephone at all & 1 \\
\hline \multicolumn{2}{|l|}{ B. Shopping } \\
\hline 1. Takes care of all shopping needs independently & 0 \\
\hline 2. Shops independently for small purchases & 1 \\
\hline 3. Needs to be accompanied on any shopping trip & 1 \\
\hline 4. Completely unable to shop & 1 \\
\hline \multicolumn{2}{|l|}{ C. Mode of Transportation } \\
\hline 1. Travels independently on public transportation or drives own car & 0 \\
\hline 2. Arranges own travel via taxi, but does not otherwise use public transportation & 0 \\
\hline 3. Travels on public transportation when accompanied by another & 0 \\
\hline 4. Travel limited to taxi or automobile with assistance of another & 1 \\
\hline 5. Does not travel at all & 1 \\
\hline \multicolumn{2}{|l|}{ D. Responsibility for own medications } \\
\hline 1. Is responsible for taking medication in correct dosages at correct time & 0 \\
\hline 2. Takes responsibility if medication is prepared in advance in separate dosage & 1 \\
\hline 3. Is not capable of dispensing own medication & 1 \\
\hline \multicolumn{2}{|l|}{ E. Ability to Handle Finances } \\
\hline 1. Manages financial matters independently (budgets, writes checks, pays rent, bills goes to bank) & 0 \\
\hline 2. Manages day-to-day purchases, but needs help with banking, major purchases, etc. & 0 \\
\hline 3. Incapable of handling money & 1 \\
\hline \multicolumn{2}{|l|}{ For women only: } \\
\hline \multicolumn{2}{|l|}{ F. Food Preparation } \\
\hline 1. Plans, prepares and serves adequate meals independently & 0 \\
\hline 2. Prepares adequate meals if supplied with ingredients & 1 \\
\hline 3. Able to heat the dishes already prepared & 1 \\
\hline 4. Needs to have meals prepared and served & 1 \\
\hline \multicolumn{2}{|l|}{ G. Housekeeping } \\
\hline 1. Maintains house alone or with occasional assistance (e.g. "heavy work domestic help") & 0 \\
\hline 2. Performs light daily tasks such as dishwashing, bed making & 0 \\
\hline 3. Performs light daily tasks but cannot maintain acceptable level of cleanliness & 0 \\
\hline 4. Needs help with all home maintenance tasks & 0 \\
\hline 5. Does not participate in any housekeeping tasks & 1 \\
\hline \multicolumn{2}{|l|}{ H. Laundry } \\
\hline 1. Does personal laundry completely & 0 \\
\hline 2. Launders small items; rinses stockings, etc. & 0 \\
\hline 3. All laundry must be done by others & 1 \\
\hline
\end{tabular}


Katz ADL scale

\begin{tabular}{|c|c|}
\hline Questions & Score \\
\hline \multicolumn{2}{|l|}{ Bathing } \\
\hline Bathes self completely & 0 \\
\hline Needs help in bathing only a single part of the body such as the back, genital area or disabled extremity & 0 \\
\hline Needs help with bathing more than one part of the body, or requires total bathing & 1 \\
\hline \multicolumn{2}{|l|}{ Dressing } \\
\hline Gets clothes from closets and drawers and puts on clothes and outer garments complete with fasteners & 0 \\
\hline May have help tying shoes & 0 \\
\hline Needs help with dressing self or needs to be completely dressed & 1 \\
\hline \multicolumn{2}{|l|}{ Toileting } \\
\hline Goes to toilet, gets on and off, arranges clothes, cleans genital area without help & 0 \\
\hline Needs help transferring to the toilet, cleaning self or uses bedpan or commode & 1 \\
\hline Does not go to the toilet & 1 \\
\hline \multicolumn{2}{|l|}{ Transferring } \\
\hline Moves in and out of bed or chair unassisted. Mechanical transferring aides are acceptable & 0 \\
\hline Needs help in moving from bed to chair or requires a complete transfer & 1 \\
\hline Does not leave the bed & 1 \\
\hline \multicolumn{2}{|l|}{ Feeding } \\
\hline Gets food from plate into mouth without help & 0 \\
\hline Needs help to cut the meal or to butter bread & 0 \\
\hline Needs total help with feeding or requires parenteral feeding & 1 \\
\hline
\end{tabular}


Number of unhealthy behaviours

\begin{tabular}{|c|c|c|c|c|c|c|}
\hline \multirow[b]{2}{*}{ Characteristics } & \multicolumn{4}{|c|}{ Number of unhealthy behaviours } & \multirow[b]{2}{*}{$\mathbf{P}^{\mathbf{a}}$} & \multirow{2}{*}{$\begin{array}{c}P(\text { age- } \\
\text { and sex- } \\
\text { adjusted) }\end{array}$} \\
\hline & $\mathbf{0}$ & $\mathbf{1}$ & 2 & 3 & & \\
\hline \multicolumn{7}{|l|}{ Baseline covariates } \\
\hline $\mathrm{N}(\%)$ & $355(8.9)$ & 1378 (34.6) & $1961(49.2)$ & $288(7.2)$ & & \\
\hline Age, mean (SD) & $73.0(4.7)$ & $73.5(5.1)$ & $74.4(5.3)$ & $73.4(5.2)$ & $<0.001$ & $<0.001$ \\
\hline Male sex, n (\%) & $110(31.0)$ & $479(34.8)$ & $785(40.0)$ & $198(68.8)$ & $<0.001$ & $<0.001$ \\
\hline \multicolumn{7}{|l|}{ Marital status, n (\%) } \\
\hline Married & $211(59.4)$ & $841(61.0)$ & $1120(57.1)$ & $186(64.6)$ & & \\
\hline Divorced, separated, or widowed & $111(31.3)$ & $425(30.8)$ & $672(34.3)$ & $86(29.9)$ & & \\
\hline Single & $33(9.3)$ & $112(8.1)$ & $169(8.6)$ & $16(5.6)$ & 0.42 & $<0.001$ \\
\hline \multicolumn{7}{|l|}{ Education, $\mathrm{n}(\%)$} \\
\hline No education or primary school & $96(27.0)$ & $421(30.6)$ & $755(38.5)$ & $96(33.3)$ & & \\
\hline Secondary school & $114(32.1)$ & $470(34.1)$ & $599(30.5)$ & $94(32.6)$ & & \\
\hline High-school or university degree & $145(40.8)$ & $487(35.3)$ & $607(31.0)$ & $98(34.0)$ & $<0.001$ & $<0.001$ \\
\hline \multicolumn{7}{|l|}{ Physical activity, n (\%) } \\
\hline High & $355(100)$ & $553(40.1)$ & $73(3.7)$ & $0(0)$ & & \\
\hline Intermediate & $0(0)$ & $580(42.1)$ & $1275(65.0)$ & $181(62.8)$ & & \\
\hline Low & $0(0)$ & $245(17.8)$ & $613(31.3)$ & $107(37.2)$ & $<0.001$ & $<0.001$ \\
\hline \multicolumn{7}{|l|}{ Consumption of fruits and vegetables, $\mathrm{n}(\%)$} \\
\hline At least once a day & $355(100)$ & $863(62.6)$ & $99(5.0)$ & $0(0)$ & & \\
\hline 4 to 6 times a week & $0(0)$ & $323(23.4)$ & $1048(53.4)$ & $125(43.4)$ & & \\
\hline Less than 4 times a week & $0(0)$ & $192(13.9)$ & $814(41.5)$ & $163(56.6)$ & $<0.001$ & $<0.001$ \\
\hline \multicolumn{7}{|l|}{ Smoking, n (\%) } \\
\hline Never smoker & $249(70.1)$ & $961(69.7)$ & $1218(62.1)$ & $0(0)$ & & \\
\hline Long-term ex-smoker (quit $\geq 15 y$ ) & $106(29.9)$ & $379(27.5)$ & $571(29.1)$ & $0(0)$ & & \\
\hline Short-term ex-smoker (quit < 15y) & $0(0)$ & $26(1.9)$ & $101(5.2)$ & $157(54.5)$ & & \\
\hline Current smoker & $0(0)$ & $12(0.9)$ & $71(3.6)$ & $131(45.5)$ & $<0.001$ & $<0.001$ \\
\hline \multicolumn{7}{|l|}{ Alcohol, n (\%) } \\
\hline Never drinker & $64(18.0)$ & $262(19.0)$ & $370(18.9)$ & $30(10.4)$ & & \\
\hline Former drinker & $5(1.4)$ & $17(1.2)$ & $59(3.0)$ & $6(2.1)$ & & \\
\hline Light and moderate drinker & $246(69.3)$ & $908(65.9)$ & $1224(62.4)$ & $160(55.6)$ & & \\
\hline Heavy drinker & $40(11.3)$ & $191(13.9)$ & $308(15.7)$ & $92(31.9)$ & $<0.001$ & $<0.001$ \\
\hline \multicolumn{7}{|l|}{ Time-dependent covariates ${ }^{b}$} \\
\hline $\mathrm{N}(\%)$ & $343(8.9)$ & $1338(34.8)$ & $1887(49.1)$ & $276(7.2)$ & & \\
\hline BMI, mean (SD) & $24.8(3.4)$ & $25.5(3.8)$ & $26.0(4.1)$ & $26.3(3.8)$ & $<0.001$ & $<0.001$ \\
\hline MMSE score, mean (SD) & $27.4(2.0)$ & $27.3(1.9)$ & $27.0(2.1)$ & $27.0(2.0)$ & $<0.001$ & $<0.001$ \\
\hline Depressive symptoms, n (\%) & $118(34.4)$ & $403(30.1)$ & $714(37.8)$ & $102(37.0)$ & 0.002 & $<0.001$ \\
\hline Bone fracture, $\mathrm{n}(\%)$ & $62(18.1)$ & $203(15.2)$ & $283(15.0)$ & $33(12.0)$ & 0.08 & 0.73 \\
\hline Falls, n (\%) & $110(32.1)$ & $401(30.0)$ & $578(30.6)$ & $86(31.2)$ & 0.97 & 0.16 \\
\hline Diabetes, n (\%) & $37(10.8)$ & $152(11.4)$ & $268(14.2)$ & $49(17.8)$ & 0.001 & 0.011 \\
\hline Parkinson's disease, n (\%) & $4(1.2)$ & $26(1.9)$ & $44(2.3)$ & $3(1.1)$ & 0.54 & 0.79 \\
\hline Vision difficulties, $\mathrm{n}(\%)$ & $51(14.9)$ & $236(17.6)$ & $335(17.8)$ & $46(16.7)$ & 0.51 & 0.12 \\
\hline Deafness, n (\%) & $61(17.8)$ & $251(18.8)$ & $418(22.2)$ & $73(26.4)$ & 0.001 & 0.01 \\
\hline Dyspnea, n (\%) & $57(16.6)$ & 257 (19.2) & $480(25.4)$ & $82(29.7)$ & $<0.001$ & $<0.001$ \\
\hline NSAID for joint pain, n (\%) & $69(20.1)$ & $314(23.5)$ & $472(25.0)$ & $52(18.8)$ & 0.53 & 0.11 \\
\hline Cancer, n (\%) & $64(18.7)$ & $206(15.4)$ & $267(14.1)$ & $48(17.4)$ & 0.23 & 0.09 \\
\hline Stroke, n (\%) & $15(4.4)$ & $70(5.2)$ & $129(6.8)$ & $12(4.3)$ & 0.18 & 0.49 \\
\hline CHD or lower-limb arteritis, n (\%) & $37(10.8)$ & $226(16.9)$ & $361(19.1)$ & $73(26.4)$ & $<0.001$ & 0.001 \\
\hline Hypertension, n (\%) & $296(86.3)$ & $1157(86.5)$ & $1672(88.6)$ & $244(88.4)$ & 0.08 & 0.44 \\
\hline Hypercholesterolemia, n (\%) & $163(47.5)$ & $612(45.7)$ & $850(45.0)$ & $114(41.3)$ & 0.15 & 0.25 \\
\hline
\end{tabular}

\footnotetext{
${ }^{a}$ Analysis of covariance for continuous variables and Mantel-Haenszel chi-square test for categorical variables.

${ }^{\mathrm{b}}$ Mean of all the measures taken during the follow-up (means) or at least one report over the follow-up (percentages).
} 
Supplementary table B. Hazard ratio of mobility impairment and disability in basic or instrumental activities of daily living (BIADL) according to physical activity, consumption of fruits and vegetables, smoking, and alcohol drinking

\begin{tabular}{|c|c|c|c|c|c|c|c|c|}
\hline \multirow[b]{3}{*}{ Characteristic } & \multicolumn{4}{|c|}{ Mobility } & \multicolumn{4}{|c|}{ BIADL } \\
\hline & \multicolumn{2}{|l|}{ Model $1^{\mathrm{a}}$} & \multicolumn{2}{|l|}{ Model $2^{b}$} & \multicolumn{2}{|l|}{ Model $1^{\mathrm{a}}$} & \multicolumn{2}{|l|}{ Model $2^{b}$} \\
\hline & HR $(95 \%$ CI $)$ & $\mathbf{P}$ & HR $(95 \%$ CI $)$ & $\mathbf{P}$ & HR $(95 \%$ CI $)$ & $\mathbf{P}$ & HR $(95 \%$ CI $)$ & $\mathbf{P}$ \\
\hline \multicolumn{9}{|l|}{ Physical activity } \\
\hline Low or intermediate vs. high & $1.33(1.19-1.48)$ & $<0.001$ & $1.31(1.17-1.46)$ & $<0.001$ & $1.59(1.39-1.82)$ & $<0.001$ & $1.56(1.36-1.79)$ & $<0.001$ \\
\hline \multicolumn{9}{|l|}{ Consumption of fruits and vegetables } \\
\hline Less than once a day vs. at least once a day & $1.26(1.13-1.40)$ & $<0.001$ & $1.25(1.12-1.39)$ & $<0.001$ & $1.22(1.09-1.37)$ & 0.001 & $1.19(1.06-1.33)$ & 0.003 \\
\hline \multicolumn{9}{|l|}{ Smoking } \\
\hline $\begin{array}{l}\text { Current or short-term ex-smoker vs. never } \\
\text { or long-term ex-smoker }\end{array}$ & $1.11(0.96-1.29)$ & 0.16 & $1.12(0.97-1.30)$ & 0.13 & $1.23(1.04-1.45)$ & 0.01 & $1.19(1.01-1.41)$ & 0.04 \\
\hline \multicolumn{9}{|l|}{ Alcohol } \\
\hline $\begin{array}{l}\text { Never, former, or heavy drinker vs. light and } \\
\text { moderate drinker }\end{array}$ & $0.91(0.82-1.01)$ & 0.09 & $0.91(0.82-1.01)$ & 0.07 & $1.05(0.94-1.17)$ & 0.36 & $1.03(0.91-1.16)$ & 0.67 \\
\hline
\end{tabular}

Of 2,235 participants (53.5\% women) without baseline mobility impairment, 1,614 (59.8\% women) developed mobility impairment.

Of 3,929 participants (60.6\% women) without baseline disability in BIADL, 1,416 (67.7\% women) developed disability in BIADL.

${ }^{a}$ Adjusted for sex, marital status, their interaction, and education

${ }^{\mathrm{b}}$ Adjusted for sex, marital status, their interaction, education, and other behaviours. 
Supplementary table C. Hazard ratio of disability according to physical activity, consumption of fruits and vegetables, smoking, alcohol drinking, and number of unhealthy behaviours in men and women.

\begin{tabular}{|c|c|c|c|c|c|c|c|c|c|c|}
\hline \multirow[b]{2}{*}{ Characteristic } & \multicolumn{5}{|c|}{$\operatorname{Men}(\mathrm{N}=1,572)$} & \multicolumn{5}{|c|}{ Women $(\mathrm{N}=\mathbf{2 , 4 1 0})$} \\
\hline & $\mathbf{N}$ & Events, $n$ & HR $(95 \%$ CI $)$ & $\mathbf{P}$ & $\mathbf{P}$ & $\mathbf{N}$ & $\begin{array}{c}\text { Events, } \\
\text { n } \\
\end{array}$ & HR $(95 \%$ CI $)$ & $\mathbf{P}$ & $\mathbf{P}$ \\
\hline \multicolumn{11}{|l|}{ Physical activity ${ }^{\mathbf{a}, \mathbf{b}}$} \\
\hline High & 385 & 62 & 1.00 (reference) & -- & & 596 & 146 & 1.00 (reference) & -- & \\
\hline Intermediate & 788 & 173 & $1.56(1.16-2.10)$ & 0.003 & & 1248 & 457 & $1.50(1.24-1.81)$ & $<0.001$ & \\
\hline Low & 399 & 140 & $2.14(1.56-2.93)$ & $<0.001$ & $<0.001^{\mathrm{e}}$ & 566 & 258 & $2.07(1.69-2.53)$ & $<0.001$ & $<0.001^{\mathrm{e}}$ \\
\hline
\end{tabular}

Consumption of fruits and vegetables ${ }^{\mathbf{a}}$

\begin{tabular}{|c|c|c|c|c|c|c|c|c|c|c|}
\hline At least once a day & 430 & 79 & 1.00 (reference) & -- & & 887 & 291 & 1.00 (reference) & -- & \\
\hline 4 to 6 times a week & 640 & 176 & $1.75(1.33-2.29)$ & $<0.001$ & & 856 & 332 & $1.12(0.95-1.31)$ & 0.17 & \\
\hline Less than 4 times a week & 502 & 120 & $1.44(1.07-1.94)$ & 0.02 & $0.02^{\mathrm{e}}$ & 667 & 238 & $1.20(1.00-1.43)$ & 0.05 & $0.04^{\mathrm{e}}$ \\
\hline
\end{tabular}

Smoking ${ }^{\mathbf{a}}$

Never smoker

Long-term ex-smoker (quit $\geq 15 \mathrm{y}$ )

Short-term ex-smoker (quit $<15 y$ )

Current smoker

$\begin{array}{lccc}456 & 111 & 1.00(\text { reference }) & -- \\ 802 & 180 & 1.08(0.85-1.37) & 0.51 \\ 192 & 56 & 1.65(1.19-2.29) & 0.003 \\ 122 & 28 & 1.25(0.79-1.96) & 0.34\end{array}$

0.03

$\begin{array}{cc}1972 & 716 \\ 254 & 86 \\ 92 & 3 \\ 92 & 25\end{array}$

$\begin{array}{ccc}716 & 1.00(\text { reference }) & -- \\ 86 & 1.05(0.84-1.32) & 0.65 \\ 34 & 1.21(0.87-1.69) & 0.25 \\ 25 & 1.23(0.84-1.79) & 0.28\end{array}$

Alcohol $^{\mathbf{a}}$

Never drinker

Former drinker

Light and moderate drinker ${ }^{\mathrm{c}}$

Heavy drinker

$\begin{array}{cccc}96 & 19 & 0.97(0.61-1.55) & 0.91 \\ 31 & 7 & 0.94(0.43-2.06) & 0.88 \\ 1027 & 251 & 1.00(\text { reference }) & -- \\ 418 & 98 & 0.96(0.76-1.23) & 0.76\end{array}$

$\begin{array}{cccc}630 & 219 & 1.03(0.88-1.21) & 0.72 \\ 56 & 26 & 1.65(1.12-2.43) & 0.01 \\ 1511 & 542 & 1.00(\text { reference }) & -- \\ 213 & 74 & 0.91(0.72-1.16) & 0.46\end{array}$

0.09

Number of unhealthy behaviours ${ }^{\mathbf{d}}$

\begin{tabular}{|c|c|c|c|c|c|c|c|c|c|c|}
\hline 0 & 110 & 16 & 1.00 (reference) & & & 245 & 60 & 1.00 (reference) & & \\
\hline 1 & 479 & 87 & $1.27(0.76-2.12)$ & 0.36 & & 899 & 291 & $1.38(1.05-1.81)$ & 0.02 & \\
\hline 2 & 785 & 210 & $2.09(1.28-3.43)$ & 0.003 & & 1176 & 477 & $1.82(1.40-2.38)$ & $<0.001$ & \\
\hline 3 & 198 & 62 & $3.23(1.88-5.54)$ & $<0.001$ & $<0.001^{\mathrm{e}}$ & 90 & 33 & $1.94(1.28-2.95)$ & 0.002 & $<0.001^{\mathrm{e}}$ \\
\hline
\end{tabular}

\footnotetext{
${ }^{a}$ Adjusted for marital status, education, and other behaviours. all others.

${ }^{c}$ 1-21 drinks per week in men, 1-14 drinks per week in women.

${ }^{\mathrm{d}}$ Adjusted for marital status and education. ${ }^{\mathrm{e}} \mathrm{P}$ for trend.
}

${ }^{\mathrm{b}}$ High: walking more than one hour per day and exercising more than once a week; low: walking less than one hour per day and exercising less than once a week; intermediate: 
Supplementary table D. Sensitivity analysis: hazard ratio of disability associated with not walking or not exercising

\begin{tabular}{lccc}
\hline Physical activity & N & HR (95\% CI) & P \\
\hline A- walks > one hour/day, exercises >once/week & 981 & 1.00 (reference) & \\
B- walks <one hour/day, exercises >once/week & 212 & $0.95(0.70-1.29)$ & 0.76 \\
C- walks > one hour/day, exercises <once/week & 1824 & $1.68(1.43-1.97)$ & $<0.001$ \\
D- walks <one hour/day, exercises <once/week & 965 & $2.16(1.82-2.56)$ & $<0.001$ \\
Exercises <once/week $v$ s. exercises >once/week & & $1.85(1.61-2.12)$ & $<0.001$ \\
\hline
\end{tabular}

Supplementary table E. Sensitivity analysis: impact of an alternative definition of physical inactivity on hazard ratio of disability according to the number of unhealthy behaviours

\begin{tabular}{cccc}
\hline $\begin{array}{l}\text { Number of unhealthy } \\
\text { behaviours }^{\mathbf{a}}\end{array}$ & HR $(\mathbf{9 5 \%} \mathbf{C I})$ & $\mathbf{P}$ & $\mathbf{P}$ \\
\hline 0 & $1.00($ reference $)$ & & \\
1 & $1.50(1.19-1.89)$ & 0.001 & \\
2 & $2.12(1.69-2.64)$ & $<0.001$ & \\
3 & $2.73(2.03-3.69)$ & $<0.001$ & $<0.001^{\mathrm{b}}$ \\
\hline
\end{tabular}

${ }^{\mathrm{a}}$ Low physical activity was defined as exercise <once/week.

${ }^{\mathrm{b}} \mathrm{P}$ for trend.

Supplementary table F. Sensitivity analysis: impact of different lag times to define short- and long-term ex-smokers on hazard ratios of disability

\begin{tabular}{|c|c|c|c|}
\hline Smoking & $\mathbf{N}$ & HR $(95 \%$ CI $)$ & $\mathbf{P}$ \\
\hline \multicolumn{4}{|l|}{15 years $^{a}$} \\
\hline Never smoker & 2428 & 1.00 (reference) & -- \\
\hline Long-term ex-smoker & 1056 & $1.02(0.88-1.19)$ & 0.78 \\
\hline Short-term ex-smoker & 284 & $1.42(1.14-1.76)$ & 0.002 \\
\hline Current smoker & 214 & $1.13(0.85-1.51)$ & 0.39 \\
\hline Current/short-term ex-smoker vs. never/long-term ex-smoker & & $1.29(1.09-1.54)$ & 0.004 \\
\hline \multicolumn{4}{|l|}{10 years $^{\mathrm{a}}$} \\
\hline Never smoker & 2428 & 1.00 (reference) & -- \\
\hline Long-term ex-smoker & 1185 & $1.04(0.90-1.21)$ & 0.59 \\
\hline Short-term ex-smoker & 155 & $1.60(1.21-2.10)$ & 0.001 \\
\hline Current smoker & 214 & $1.13(0.85-1.51)$ & 0.39 \\
\hline Current/short-term ex-smoker vs. never/long-term ex-smoker & & $1.32(1.08-1.61)$ & 0.01 \\
\hline \multicolumn{4}{|l|}{5 years $^{\mathrm{a}}$} \\
\hline Never smoker & 2428 & 1.00 (reference) & -- \\
\hline Long-term ex-smoker & 1265 & $1.06(0.92-1.23)$ & 0.41 \\
\hline Short-term ex-smoker & 75 & $1.96(1.36-2.82)$ & $<0.001$ \\
\hline Current smoker & 214 & $1.13(0.85-1.51)$ & 0.39 \\
\hline Current/short-term ex-smoker vs. never/long-term ex-smoker & & $1.32(1.05-1.65)$ & 0.02 \\
\hline
\end{tabular}

${ }^{a}$ Lag time used to define short- and long-term ex-smokers. 
Supplementary table G. Sensitivity analysis: varying definitions of unhealthy alcohol drinking (exclusion of abstainers or heavy drinkers)

\begin{tabular}{llll}
\hline \multicolumn{1}{c}{ Characteristic } & HR (95\% CI) & P & P \\
\hline $\begin{array}{l}\text { Exclusion of abstainers } \\
\text { Former or heavy drinker vs. light and moderate drinker }\end{array}$ & $1.03(0.88-1.21)$ & 0.69
\end{tabular}

Number of unhealthy behaviours

\begin{tabular}{|c|c|c|c|}
\hline 0 & 1.00 (reference) & & \\
\hline 1 & $1.46(1.08-1.99)$ & 0.01 & \\
\hline 2 & $1.89(1.40-2.54)$ & $<0.001$ & \\
\hline 3 or 4 & $2.08(1.51-2.86)$ & $<0.001$ & $<0.001^{\mathrm{a}}$ \\
\hline \multicolumn{4}{|l|}{ clusion of heavy drinkers } \\
\hline mer or never drinker vs. light and moderate drinker & $1.09(0.94-1.25)$ & 0.26 & \\
\hline \multicolumn{4}{|l|}{ mber of unhealthy behaviours } \\
\hline 0 & 1.00 (reference) & & \\
\hline 1 & $1.45(1.09-1.93)$ & 0.01 & \\
\hline 2 & $1.87(1.42-2.48)$ & $<0.001$ & \\
\hline 3 or 4 & $2.38(1.77-3.20)$ & $<0.001$ & $<0.001^{\mathrm{a}}$ \\
\hline
\end{tabular}

${ }^{\mathrm{a}} \mathrm{P}$ for trend.

Supplementary table H. Sensitivity analysis: exclusion of participants who recovered from disability during the follow-up

\begin{tabular}{|c|c|c|c|c|c|c|}
\hline \multirow[b]{2}{*}{$\begin{array}{l}\text { Number of unhealthy } \\
\text { behaviours }\end{array}$} & \multicolumn{3}{|c|}{ Column $A^{a}$} & \multicolumn{3}{|c|}{ Column B ${ }^{\mathbf{b}}$} \\
\hline & HR $(95 \%$ CI $)$ & $\mathbf{P}$ & $\mathbf{P}$ & HR (95\% CI) & $\mathbf{P}$ & $\mathbf{P}$ \\
\hline 0 & 1.00 (reference) & & & 1.00 (reference) & & \\
\hline 1 & $1.35(1.01-1.79)$ & 0.04 & & $1.37(1.04-1.81)$ & 0.03 & \\
\hline 2 & $1.94(1.47-2.56)$ & $<0.001$ & & $1.97(1.51-2.58)$ & $<0.001$ & \\
\hline 3 & $2.66(1.87-3.77)$ & $<0.001$ & $<0.001^{\mathrm{c}}$ & $2.64(1.87-3.71)$ & $<0.001$ & $<0.001^{\mathrm{c}}$ \\
\hline
\end{tabular}

\footnotetext{
${ }^{a}$ After exclusion of 297 participants who became non-disabled during the follow-up.

${ }^{\mathrm{b}}$ After exclusion of 243 participants who became non-disabled and remained disability-free throughout the follow-up.

${ }^{\mathrm{c}} \mathrm{P}$ for trend.
} 
Supplementary table I. Sensitivity analysis: odds ratio (multinomial logistic regression) for the hierarchical disability score according to the number of unhealthy behaviours (waves 1,4 , and 6 )

\begin{tabular}{|c|c|c|c|c|}
\hline $\begin{array}{l}\text { Number of } \\
\text { unhealthy } \\
\text { behaviours }\end{array}$ & $\begin{array}{c}\text { Fully } \\
\text { independent }\end{array}$ & $\begin{array}{l}\text { Dependent for } \\
\text { mobility only }\end{array}$ & $\begin{array}{c}\text { Dependent for } \\
\text { mobility and IADLs } \\
\text { but not ADLs }\end{array}$ & $\begin{array}{c}\text { Dependent in all } \\
\text { domains }\end{array}$ \\
\hline \multicolumn{5}{|c|}{ Wave1 $(n=3,748)$} \\
\hline 0 & 1.00 (reference) & 1.00 (reference) & 1.00 (reference) & 1.00 (reference) \\
\hline 1 & 1.00 (reference) & $1.04(0.81-1.35)$ & $3.39(1.20-9.62)$ & Not estimable ${ }^{a}$ \\
\hline 2 & 1.00 (reference) & $1.47(1.15-1.89)$ & $5.41(1.94-15.10)$ & Not estimable $^{a}$ \\
\hline 3 & 1.00 (reference) & $1.91(1.35-2.71)$ & $5.18(1.53-17.48)$ & Not estimable $^{a}$ \\
\hline \multicolumn{5}{|c|}{ Wave4 $(n=2,575)$} \\
\hline 0 & 1.00 (reference) & 1.00 (reference) & 1.00 (reference) & 1.00 (reference) \\
\hline 1 & 1.00 (reference) & $1.03(0.75-1.41)$ & $2.18(1.26-3.76)$ & Not estimable \\
\hline 2 & 1.00 (reference) & $1.43(1.04-1.97)$ & $4.16(2.43-7.12)$ & Not estimable $^{a}$ \\
\hline 3 & 1.00 (reference) & $2.43(1.48-3.99)$ & $12.20(6.10-24.40)$ & Not estimable ${ }^{a}$ \\
\hline \multicolumn{5}{|c|}{ Wave6 $(n=1,480)$} \\
\hline 0 & 1.00 (reference) & 1.00 (reference) & 1.00 (reference) & 1.00 (reference) \\
\hline 1 & 1.00 (reference) & $0.80(0.52-1.23)$ & $1.36(0.77-2.42)$ & $1.36(0.15-12.23)$ \\
\hline 2 & 1.00 (reference) & $0.78(0.50-1.20)$ & $1.61(0.91-2.85)$ & $2.74(0.34-22.39)$ \\
\hline 3 & 1.00 (reference) & $2.02(1.00-4.12)$ & $4.22(1.74-10.23)$ & Not estimable $^{\mathrm{b}}$ \\
\hline
\end{tabular}

${ }^{\mathrm{a}}$ Odds ratios were not estimable because none of the participants dependent for all domains had 0 unhealthy behaviours.

${ }^{\mathrm{b}}$ Odd ratio was not estimable because none of the participants dependent for all domains had 3 unhealthy behaviours. 
Supplementary Figure A. Flow-chart of the study.

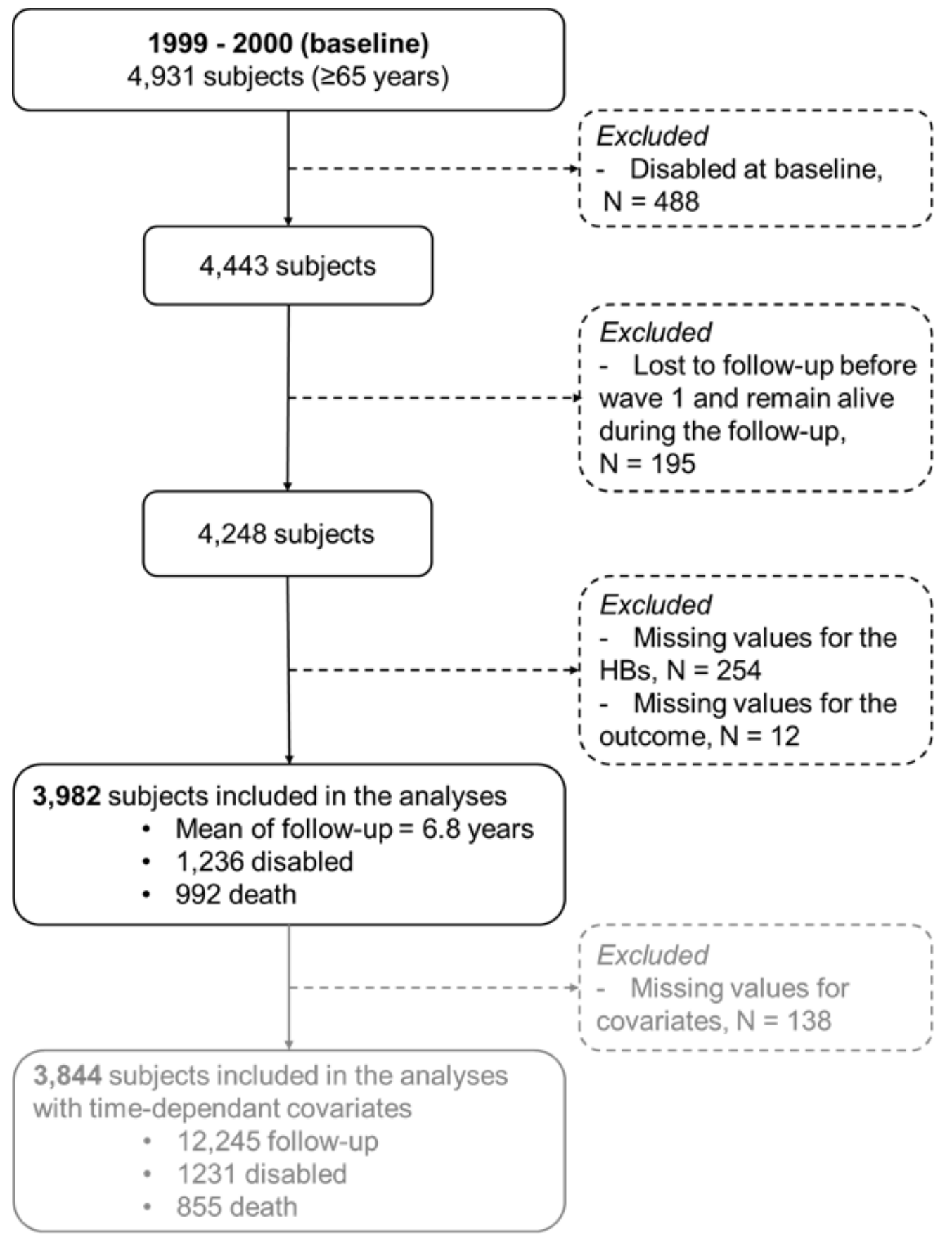


Supplementary Figure B. Hazard ratio of disability according to the number of the four unhealthy behaviours: hierarchical indicator of disability (panel A), mobility (panel B), and disability in basic or instrumental ADLs (BIADL) (panel C)
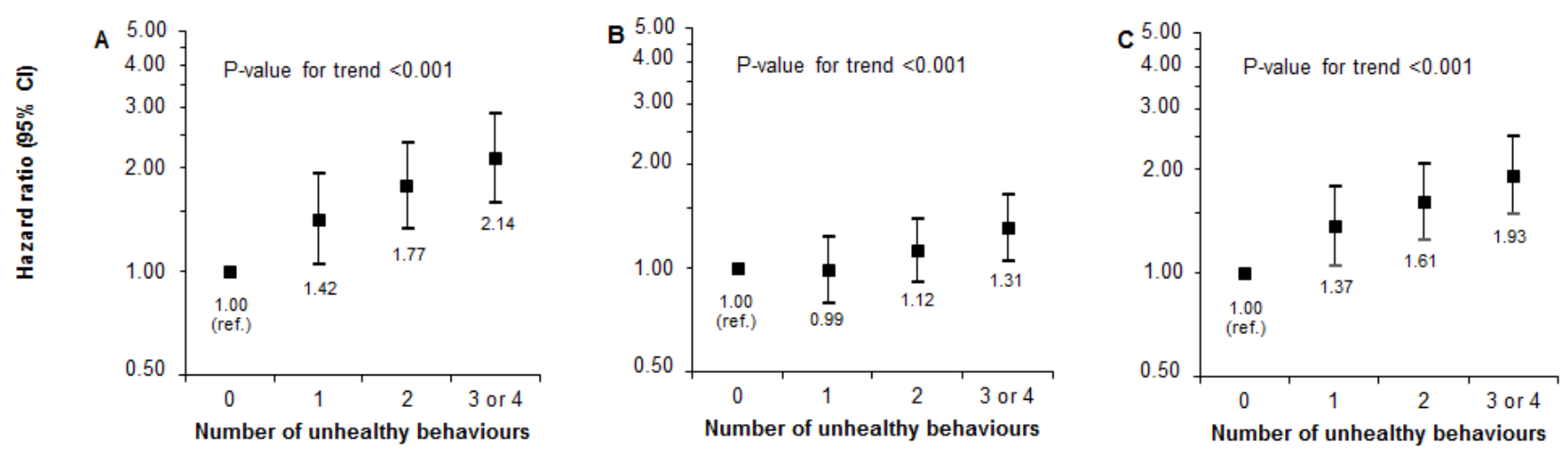

Hazard ratios (95\% confidence intervals) were computed using interval-censored survival models with age as the time-scale and were adjusted for sex, marital status, their interaction, and education.

$6 \%$ of the participants had zero, $26 \%$ had one, $42 \%$ had two, $23 \%$ had three, and $3 \%$ four unhealthy behaviours; as few participants had four unhealthy behaviours, we grouped them with those with three. 